\title{
In-Space Propulsion Solar Electric Propulsion Program Overview of 2006
}

\author{
Randy M. Baggett ${ }^{*}$ and Wendy W. Hulgan ${ }^{\dagger}$ \\ NASA - Marshall Space Flight Center, Huntsville, AL 35812 \\ John W. Dankanich ${ }^{\ddagger}$ and Robert T. Bechtel ${ }^{\S}$ \\ Gray Research, Inc., Huntsville, AL, 35806
}

\begin{abstract}
The primary source of electric propulsion development throughout NASA is implemented by the In-Space Propulsion Technology Project at the NASA MSFC under the management of the Science Mission Directorate. The Solar Electric Propulsion technology area's objective is to develop near and mid-term SEP technology to enhance or enable mission capture while minimizing risk and cost to the end user. Major activities include developing NASA's Evolutionary Xenon Thruster (NEXT), implementing a Standard Architecture, and developing a long life High Voltage Hall Accelerator (HiVHAC). Lower level investments include advanced feed system development, advanced cathode testing and xenon recovery testing. Progress on current investments and future plans are discussed.
\end{abstract}

\section{Acronyms}

\begin{tabular}{llll} 
ASOA & Advanced State-of-the-Art & NRA & \multicolumn{2}{c}{ NASA Research Announcement } \\
DCA & Discharge Cathode Assembly & NSTAR NASA Solar Electric Propulsion \\
DCIU & Digital Control Interface Unit & & Technology Application Readiness \\
EM & Engineering Model & PAT & Performance Acceptance Test \\
FCM & Flow Control Module & PCM & Pressure Control Module \\
GRC & Glenn Research Center & PM & Prototype Model \\
HET & Hall Effect Thruster & PMS & Propellant Management System \\
HiVHAC & High Voltage Hall Accelerator & PPU & Power Processing Unit \\
IPS & Ion Propulsion System & SA & Standard Architecture \\
ISPT & In-Space Propulsion Technology & SMD & Science Mission Directorate \\
JPL & Jet Propulsion Laboratory & TRL & Technology Readiness Level \\
NCA & Neutralizer Cathode Assembly & TRV & Technology Requirements and Validation \\
NEXT & NASA's Evolutionary Xenon Thruster & XFS & Xenon Feed System
\end{tabular}

\section{Introduction}

$I^{n}$ FY06 the ISPT has made significant investments in ion propulsion system technologies. The primary investment in ISPT electric propulsion technologies has been through the NEXT program developing the next generation ion propulsion system. ISPT has also made investments in higher risk technologies with significant benefits over SOA systems that include a long life high voltage Hall thruster and an advanced xenon feed system. Last, ISP has initiated an evaluation of the potential benefit of using commercially available electric propulsion systems for NASA science mission applications. If these commercial systems were qualified to meet NASA science mission requirements, the use of off-the-shelf type hardware could significantly lower the cost of future EP systems.

\footnotetext{
* SEP Technology Area Manager, In-Space Propulsion Technology Office, VP51, Randy.M.Baggett@nasa.gov, Member, AIAA.

${ }^{\dagger}$ Lead Systems Engineer, In-Space Propulsion Technology Office, VP51, Wendy.Hulgan@nasa.gov, Member, AIAA.

${ }^{\ddagger}$ Aerospace Engineer, In-Space Propulsion, John.Dankanich@nasa.gov, Member, AIAA.

${ }^{\S}$ Senior Engineer, In-Space Propulsion, Robert.Bechtel@gray-research.com, Member, AIAA.
} 


\section{NEXT}

The NEXT ion propulsion system was selected in 2001 to develop a higher power, longer life thruster based on the heritage of the NSTAR program. The NEXT development activity is led by the Glenn Research Center teamed with the Jet Propulsion Laboratory, Aerojet Redmond Rocket Center, University of Michigan, Colorado State University, and L-3 Communications ETI. The phase I development activities concluded in 2003 with the delivery of three engineering model thrusters, a breadboard power processing unit, a breadboard propellant management system, integrated system performance and thruster wear testing. ${ }^{1}$

The current phase of development activities include two prototype model level thrusters manufactured by Aerojet, an EM PPU manufactured by L-3 Comm ETI, an EM PMS and digital control interface unit simulator developed by Aerojet, two breadboard gimbals built by a JPL/Swales team,

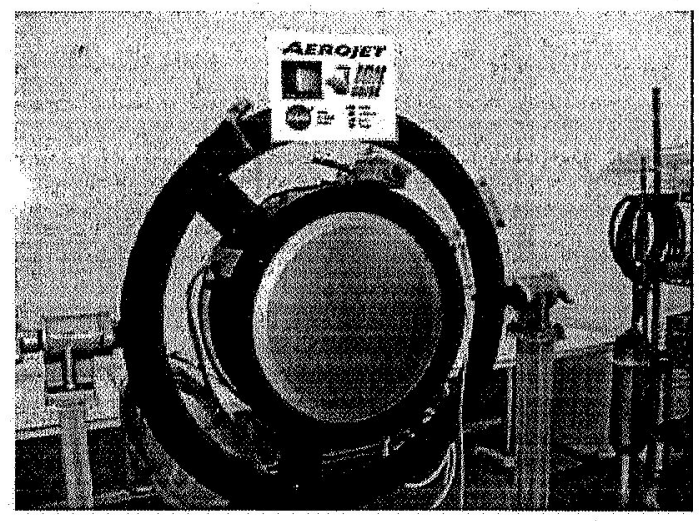

Figure 1: NEXT PM Thruster with Shipping Adaptor. performance and environmental subsystem testing, integrated system testing, and the start of a thruster qualification life test.

The NEXT program has made significant progress over the past year. Major accomplishments include delivery and performance acceptance testing of the first PM thruster, performance and environmental testing of an EM PMS, multi-thruster array testing, and over 5,500 hours and 110 kilograms of Xenon propellant used in EM3 wear testing.

\section{A. PM1 Thruster Manufacturing and Acceptance Testing}

Aerojet successfully manufactured and delivered the first PM thruster to GRC in January, 2006. The PM1 optics assembly has a mass of $3.26 \mathrm{~kg}$. The initial alignment was within $11 \mu \mathrm{m}$ in the radial direction and $7.3 \mu \mathrm{m}$ in the axial direction; well within the $25 \mu \mathrm{m}$ and $13 \mu \mathrm{m}$ requirements, respectively. The optics assembly demonstrated the ability to reassemble and re-measure the optics within $1.3 \mu \mathrm{m}$ of the original alignment in less than seven hours. The discharge cathode and neutralizer cathode assemblies successfully passed $10^{-8}$ sccs He leak tests and were installed on the PM thruster. The final masses were $550 \mathrm{~g}$ and $470 \mathrm{~g}$ for the DCA and NCA respectively. The final thruster assembly has a mass of $12.7 \mathrm{~kg}$ or $13.5 \mathrm{~kg}$ with the harnesses.

The PM1 Performance Acceptance Test (PAT) was completed in February of 2006. The objectives of the PAT are to assess the prototype model performance, validate the PM thruster design, and validate successful technology transfer with commercial manufacturing processes. The PAT test also provides both steady-state and transient thermal data on a PM thruster for thermal margin validation and model development.

The PM1 thruster successfully ignited during the first attempt. The TRV requirements of the NEXT thruster are to perform greater than $67 \%$ efficiency and 4,050 s of specific impulse at full power. The PAT test was conducted on the multi-thruster array in VF6. The results of the PAT test are shown in table 1. The PM thruster met or exceeded the EM performance at all operating conditions tested. The numbers in red are the thruster results and the numbers in blue are the requirements established by the EM thruster performance. The PAT also demonstrated a lower recycle rate, increased plume mode operation margin for the neutralizer at low beam currents, and significantly reduced steady-state temperatures compared to the EM thruster design. The initial PAT did expose one necessary rework item, the DCA conducted too much heat leading to delayed emitter ignition times. The DCA redesign was minor and has undergone successful demonstration with a second PAT on PM1, and will be further validated with the PM2 thruster. 
Table 1: Comparison of TRV requirements and PM1 PAT test results.

\begin{tabular}{|c|c|c||c|c|c|c|c|c|}
\hline $\mathrm{Vb}, \mathrm{V}$ & $\mathrm{Jb}_{\mathbf{2}} \mathrm{A}$ & $\mathrm{Pin}, \mathrm{kW}$ & $\begin{array}{c}\text { TRV Eff. } \\
\text { Req. }\end{array}$ & Thrust Eff. & $\begin{array}{c}\text { TRV Thrust } \\
\text { Req., } \mathrm{mN}\end{array}$ & Thrust, $\mathrm{mN}$ & $\begin{array}{c}\text { TRV Isp } \\
\text { Req., sec }\end{array}$ & Isp, sec \\
\hline 1800 & 3.524 & 6.860 & 0.708 & 0.710 & 236 & 237 & 4188 & 4190 \\
\hline 1180 & 3.525 & 4.700 & 0.677 & 0.680 & 192 & 192 & 3393 & 3395 \\
\hline 1800 & 2.003 & 3.990 & & 0.711 & & 134 & & 4315 \\
\hline 1179 & 2.002 & 2.750 & & 0.676 & & 108 & & 3495 \\
\hline 1800 & 1.202 & 2.435 & 0.645 & 0.647 & 80 & 80 & 3999 & 4000 \\
\hline 1179 & 1.203 & 1.715 & 0.606 & 0.606 & 65 & 65 & 3240 & 3245 \\
\hline 679 & 1.202 & 1.135 & & 0.524 & & 49 & & 2455 \\
\hline
\end{tabular}

\section{B. Multi-thruster Array Testing}

The NEXT program successfully completed a $3+1$, three operating thrusters and one spare, multi-thruster array test in December, 2005., ${ }^{2,4,5,6,7}$ The multi-thruster test represents the most comprehensive test of multiple ion thrusters firing simultaneously by NASA in two decades using SOA thrusters and diagnostics. The objective of the test was to determine the impact of startup, throttling, and shutdown of adjacent operating thrusters. The test array is shown in figure 2. During the test EM1, EM4, and EM5 were all operated successfully with EM2 serving as a thruster spare that was not operated, but contained multiple diagnostics.

The multi-thruster tests successfully demonstrated $1+1,2+1$, and $3+1$ thruster configurations. The setup also allowed for testing with two operating thrusters at a separation distance of both $0.64 \mathrm{~m}$ and $0.91 \mathrm{~m}$ center-to-center. EM1 thruster was also placed on a gimbal mount capable of rotating up to $12^{\circ}$. Multi-thruster testing also evaluated the effect of neutralizer placement and distance from the operating thrusters, in addition to operating multiple thrusters on a single neutralizer.

The performance observed for a thruster in an array configuration appears to be consistent with that measured during single thruster operation. The minor observed effect of multi-thruster operation, such as an increase in accelerator current, appears to correlate to a facility effect due to an increase in background pressure. There were no demonstrable thruster-tothruster interactions observed during steady-state, throttling, or recycle events. The preliminary results were very positive, indicating that thruster life established through single thruster long duration testing may accurately reflect expected life during multi-

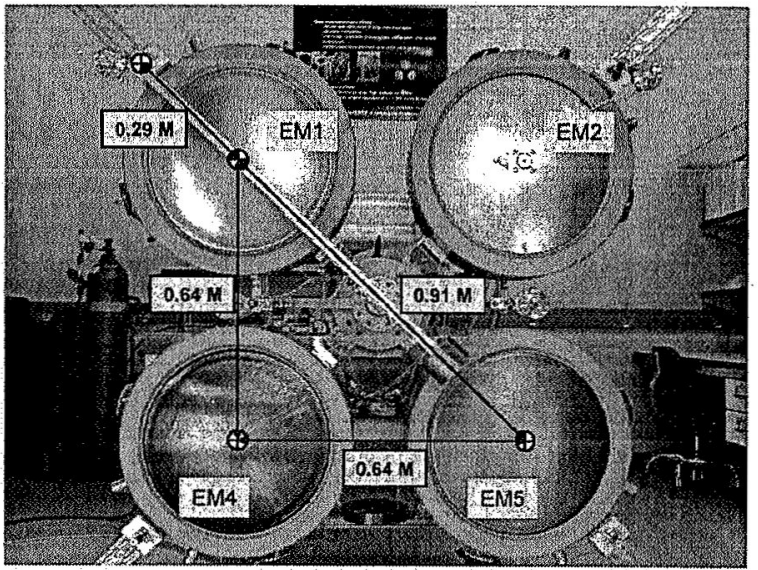

Figure 2: NEXT Multi-thruster test array. thruster operation and that a single neutralizer has no negative impacts for multiple thruster operation. Using a single neutralizer improves multi-thruster performance, particularly at low power operation.

Another objective of the test was multi-thruster plume characterization. The test utilized several diagnostics to create ion current density, plasma potential and electron temperature maps, record ion energies and plasma flux at the array, and characterize neutralizer plasma during steady-state, throttling, start-up, shutdown and thruster gimbaling operation. Overall, there were no plume-to-plume interactions observed. Preliminary results indicate little change in plume profile due to multi-thruster operation, neutralizer configuration or thruster gimbaling, and that superposition may be sufficient to predict multi-thruster plume profiles. 


\section{EM3 Wear Testing}

The EM3 wear test began on June 5, 2005. As of May 1, 2006, the EM3 wear tests had accumulated more than $5,000 \mathrm{hrs}$ of operation and processed more than $100 \mathrm{~kg}$ of xenon. Figure 3 shows the propellant throughput rate over time. The NEXT thruster has already processed more propellant than both the DS1 flight demonstration and the NSTAR 8,200 hour life-demonstration test.

The test article thruster, EM3, is GRCbuilt with Aerojet-built prototype model ion optics. The materials, processes, and dimensions of the thruster hardware exposed

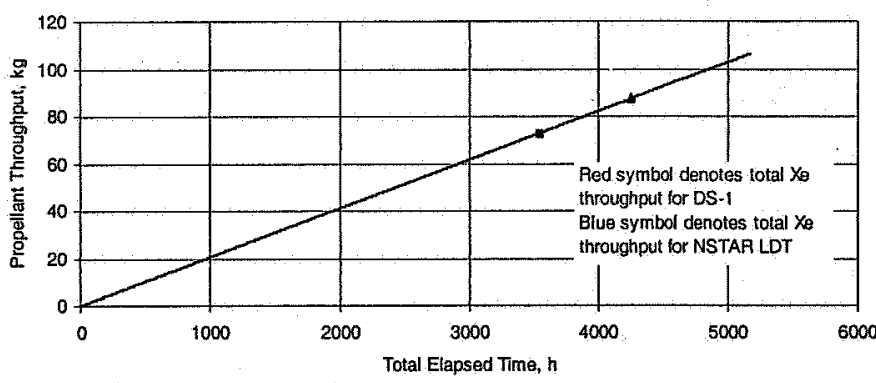

Figure 3: NEXT LDT Propellant throughput over time. to the plasma erosion processes are made to be identical to the PM thruster. The wear test objective is to identify and characterize thruster wear mechanisms and operation and compare results to predictive models. Initially, the EM3 wear test had been planned to continue until demonstrating that the thruster's qualification propellant throughput is greater than $450 \mathrm{~kg}$. Under the baseline plan, the NEXT thruster will have demonstrated its qualification level throughput in 2009. The EM3 thruster may undergo destructive analysis and be replaced with a prototype model thruster for the full a full qualification level life test.

A NEXT service life assessment has determined the full-power life of the NEXT thruster to be greater than 730 kg. ${ }^{8}$ The EM3 wear test results are consistent with the predicted wear rates. The thruster has shown no change in thruster performance and no noticeable change in grid gap. The predicted life limitations and failure mechanisms are of the NEXT IPS are shown in Table 2. The propellant throughput and total impulse capability of the NEXT thruster are significant improvements over the SOA NSTAR engine.

Table 2: Summary of NEXT Thruster Life Assessment.

\begin{tabular}{|c|c|c|c|c|c|}
\hline \multirow[b]{2}{*}{ Component } & \multirow[b]{2}{*}{ Failure Mechanism } & \multicolumn{4}{|c|}{ Xenon Throughput, $\mathrm{kg}$} \\
\hline & & $\begin{array}{l}3.52 \mathrm{~A} I_{b} \\
1800 \vee V_{b}\end{array}$ & $\begin{array}{l}1.20 \mathrm{~A} I_{b} \\
1800 \mathrm{~V} V_{b}\end{array}$ & $\begin{array}{l}1.20 \mathrm{~A} I_{b} \\
1179 \mathrm{VV}_{b}\end{array}$ & $\begin{array}{l}1.20 \mathrm{~A} \mathrm{I}_{b} \\
679 \mathrm{~V} V_{b}\end{array}$ \\
\hline \multirow{3}{*}{ DCA } & Insert Barium Depletion & 1450 & 5200 & 4100 & 3700 \\
\hline & Excessive Wear of Orifice Plate & \multicolumn{4}{|c|}{ No excessive wear prior to excessive keeper wear } \\
\hline & Excessive Wear of Keeper & 1800 & TBD & TBD & TBD \\
\hline \multirow{4}{*}{ NCA } & Insert Barium Depletion & 1600 & 2400 & 2400 & 2400 \\
\hline & Excessive Wear of Orifice Plate & \multicolumn{4}{|c|}{ No excessive wear } \\
\hline & Excessive Wear of Keeper & $>800$ & TBD & TBD & TBD \\
\hline & Neutralizer orifice clogging & \multicolumn{4}{|c|}{ Controlled through requirements } \\
\hline \multirow{2}{*}{$\begin{array}{l}\text { Accelerator } \\
\text { Electrode }\end{array}$} & $\begin{array}{l}\text { Pit and Groove Wear / } \\
\text { Structural Failure }\end{array}$ & $>730$ & $>800$ & $\mathrm{TBD}$ & TBD \\
\hline & $\begin{array}{l}\text { Aperture Enlargement / } \\
\text { Electron Backstreaming }\end{array}$ & $>730$ & $>800$ & TBD & TBD \\
\hline $\begin{array}{l}\text { Screen } \\
\text { Electrode }\end{array}$ & Excessive Wear & \multicolumn{4}{|c|}{ No excessive wear anticipated } \\
\hline $\begin{array}{l}\text { Optics } \\
\text { Assembly }\end{array}$ & An Unclear able Short & \multicolumn{4}{|c|}{ Controlled through requirements } \\
\hline \multirow{2}{*}{$\begin{array}{l}\text { Discharge } \\
\text { Chamber }\end{array}$} & $\begin{array}{l}\text { Flake Retention of Sputtered } \\
\text { Material }\end{array}$ & 1850 & TBD & TBD & TBD \\
\hline & $\begin{array}{l}\text { Magnet Temperatures } \\
\text { Excessive }\end{array}$ & \multicolumn{4}{|c|}{$100^{\circ} \mathrm{C}$ margin (dependent on mission) } \\
\hline $\begin{array}{l}\text { High Voltage } \\
\text { Propellant } \\
\text { Isolators }\end{array}$ & $\begin{array}{l}\text { Deposition of Sputter Material } \\
\text { Degrading Voltage Standoff }\end{array}$ & \multicolumn{4}{|c|}{$\begin{array}{l}\text { Monitoring of manufacturing process, Design } \\
\text { verification test ongoing }\end{array}$} \\
\hline
\end{tabular}




\section{PPU, PMS, and Gimbal Status}

The phase II NEXT activities include the delivery of an EM PPU, EM PMS, and breadboard gimbal. The subsystem hardware will undergo environmental testing to qualification levels and integrated system testing.

The PPU to operate the NEXT thruster is being developed by L3, Torrance, CA (formerly Boeing Electron Dynamics Division). The Phase II engineering model topologies are based on the breadboard developed during Phase I with some modifications to the screen supply to improve efficiency especially at low power. The EM PPU is also designed for vibration and thermal vacuum environmental qualification testing.

The screen supply for the EM PPU is modular in design, being made up of six modules which can be individually turned off as the power requirement decreases. This approach significantly increased the efficiency at low power such that it is near $90 \%$ at minimum power and near $95 \%$ at maximum power. The last of the six modules is currently being completed. Full screen supply integration and test is scheduled for May ' 06.

Some minor changes are being implemented in the discharge supply, and all other supplies and subassemblies are nearly complete. The chassis design is nearly complete and integration of the entire PPU is scheduled to begin in June.

The NEXT propellant management system is being developed by Aerojet. It is designed to independently control the propellant flow rates to the main discharge chamber, discharge cathode, and neutralizer cathode. It has already passed baseline flow calibration testing, random vibration, and post-vibe functional testing. Thermal vacuum, multi-string testing and integration with a NEXT thruster is scheduled for FY07.

The breadboard gimbal development has been led by JPL and Swales Aerospace. The integrated gimbal and thruster performance and vibration testing is planned for the summer of 2006 . In preparation for the NEXT thruster delivery, a gimbal shock and vibration test was completed in March, 2006, with a mass simulator. The objectives of the mass simulator testing were to validate the breadboard gimbal to NEXT protoflight random vibration specifications, acquire gimbal-thruster interface data for additional thruster analysis, and validate procedures for the NEXT thruster

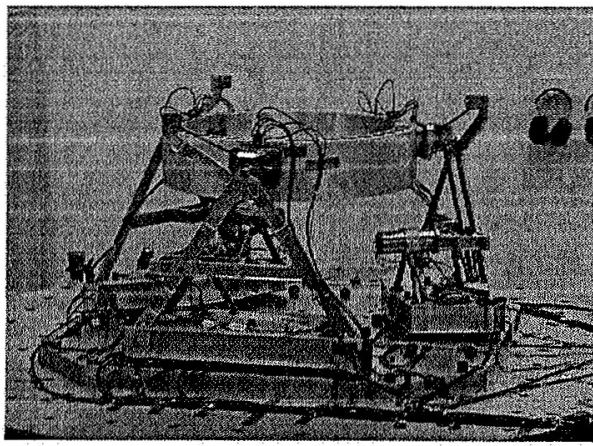

Figure 4: NEXT Gimbal Assembly. vibration testing.

\section{HiVHAC}

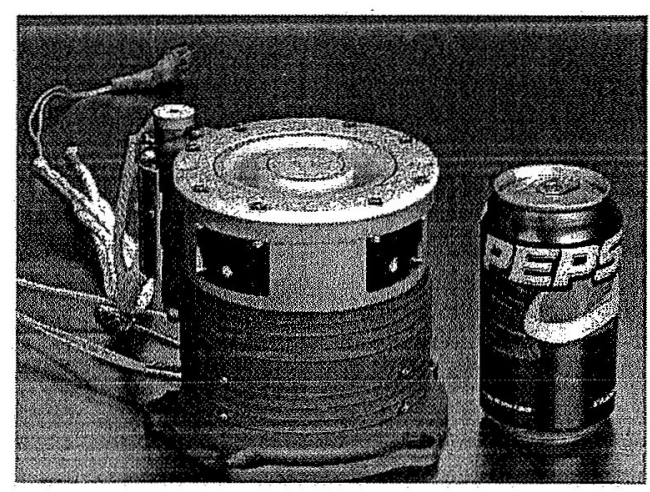

Figure 5: NASA 77M HiVHAC Thruster.

The HiVHAC thruster development project was selected in 2003 to develop a 6-8 $\mathrm{kW}$ Hall thruster with moderate Isp for Flagship class missions. The project is led by NASA's GRC teamed with Aerojet, JPL and the University of Michigan. After the focus of ISPT project turned from large missions to smaller Discovery and New Frontiers missions, the HiVHAC project was re-vectored to develop a smaller thruster with a lower maximum power level specifically to increase low power performance and reduce cost for Discovery class electric propulsion missions ${ }^{10}$. In March 2005 a prototype HiVHAC thruster was experimentally evaluated ${ }^{11}$. The demonstrated performance confirmed the capability of this technology to provide mission enabling performance for certain science mission applications through a unique combination of a large throttle range and a large specific impulse range. The range of operational power for this thruster was from $0.2-2.8 \mathrm{~kW}$. Beginning in October of 2005 the focus of project became thruster technology developments needed to make possible thruster operational lifetimes needed for the targeted cost constrained robotic science missions Initially mission analysis was undertaken to quantify operational lifetime capability needs. These analyses concluded that lifetime had a much weaker influence of mission performance than did thruster throughput capability. As a result the maximum thruster power level was increased from 2.8 to $3.5 \mathrm{~kW}$. This change allowed equivalent propellant throughput with an operational lifetime reduction of more than $40 \%$. Despite this reduction in required operational lifetime, the needs of many 
targeted robotic science missions exceed the throughput capability achievable without advanced development. Two different approaches to increasing HiVHAC propellant throughput have been identified and are under development. These two different approaches offer parallel development paths referred to as the state-of-the-art (SOA) approach and an advanced state-of-the-art (ASOA) approach. Each of these efforts is discussed below.

\section{A. SOA HiVHAC Thruster}

The SOA HiVHAC thruster development is a low risk approach to extending thruster lifetime by incorporating a number of design features previously proven to enhance thruster lifetime. The primary challenge of this approach is to ensure that discharge channel erosion is minimized sufficiently to ensure full power $(3.5 \mathrm{~kW})$ operation for a minimum of 7500 hours. This operational lifetime corresponds to a nominal propellant throughput of $150 \mathrm{~kg}$. This throughput capability must be achieved at a

Table 3: Comparison of BPT-4000 and HiVHAC thrusters.

\begin{tabular}{|l|c|c|}
\cline { 2 - 3 } \multicolumn{1}{c|}{} & BPT-4000 & HIVHAC \\
\hline Thruster Max. Power & $4.5 \mathrm{~kW}$ & $3.6 \mathrm{~kW}$ \\
\hline Throttle Ratio & $4: 1^{*}$ & $12: 1$ \\
\hline Operating Voltage & $300 \mathrm{~V}-400 \mathrm{~V}$ & $200 \mathrm{~V}-800 \mathrm{~V}$ \\
\hline Specific Impulse & $900 \mathrm{~s}-1500 \mathrm{~s}$ & $900 \mathrm{~s}-2900 \mathrm{~s}$ \\
\hline Thrust & $161 \mathrm{mN}-282 \mathrm{mN}$ & $20 \mathrm{mN}-150 \mathrm{mN}$ \\
\hline Thruster Alpha & $2.7 \mathrm{~kg} / \mathrm{kW}$ & $1.5 \mathrm{~kg} / \mathrm{kW}$ \\
\hline Lifetime & $\sim 9,000 \mathrm{hrs}^{* *}$ & $(>30,000 \mathrm{hrs}$ ASOA $)$ \\
\hline
\end{tabular}

discharge voltage of 700 Volts. The high voltage operation allows the thruster to operate at specific impulses much higher than conventional Hall thrusters. The high voltage also allows the thruster to operate at a much higher power density than conventional Hall thrusters. A comparison of the HiVHAC thruster to a conventional HET is shown in Table 3. A SOA prototype thruster designed to provide a $150 \mathrm{~kg}$ throughput has been fabricated and will be evaluated to confirm this capability.

\section{B. ASOA HiVHAC Thruster}

The ASOA HiVHAC thruster development approach is a less traditional approach to extending thruster lifetime with the potential of enabling lifetimes in excess of 15,000 hours and throughputs in excess of $300 \mathrm{~kg}$. An ASOA. laboratory-model thruster designed to provide a $150 \mathrm{~kg}$ throughput has been fabricated and will be evaluated to confirm this capability. Further details about either the prototype SOA thruster or the ASOA laboratory-model thruster cannot be provided to due to export regulations.

\section{Wear Characterization and Modeling}

In order to predict the lifetime and throughput capability of both SOA and ASOA thrusters an effort to accurately numerically simulate discharge channel erosion was undertaken. This activity, lead by the University of Michigan, was based on previous Hall thruster discharge channel wear simulations ${ }^{12}$. Developments needed to allow these analytic tools to be used in support of the HiVHAC program are a result of the increase in discharge voltage, and power density of the HiVHAC thruster relative to conventional HETs. In order to allow early benchmarking of this improved simulation capability, the $2.8 \mathrm{~kW}$ prototype thruster demonstrated in 2005 was utilized in a number of abbreviated accelerated wear tests. Initial bench-marking of the improved wear simulation against experimental data have provided the HiVHAC project with confidence that both the SOA and ASOA thruster development approaches will be successful in achieving their lifetime and throughput goals. Additional erosion data will be generated and continued modeling effort will both be used to mitigate the thruster lifetime challenges as the HiVHAC project proceeds. In addition, progress has been made in the modeling of other degradation mechanisms with Hall thrusters operated in a variety of modes. This is of vital importance not only to projecting the operational lifetime of advanced technology thrusters developed within NASA but also in adapting commercial thrusters designed for earth orbital operation to use in Deep Space where they must be throttled over a much broader range.

\section{Advanced Xenon Feed System}


An advanced xenon feed system development was selected under the 2002 ROSS NRA award and initially funded in 2004 for Lightweight, Reliable Xenon Feed System components based on All-Metal ChEMS ${ }^{\mathrm{TM}}$ Manufacturing Technology. The task is led by VACCO Industries, Inc. of South El Monte, California, seeks to improve the reliability of ion propulsion feed systems while decreasing mass and volume over SOA XFS technologies as shown in Table 3. Following a user requirements definition study early in the base phase, the conceptual feed system architecture was changed from a digital fuel control array to an architecture that utilizes piezoelectrically actuated proportional micro valves to meet flow accuracies and reliability requirements while maintaining reduced mass and volume. VACCO has utilized IR\&D funds to develop the proportional micro valves.

Table 4: Comparison NEXT and ChEMS ${ }^{\mathrm{TM}}$ XFS.

\begin{tabular}{|c|c|c|}
\hline & NEXT System & ChEMSR System \\
\hline $\begin{array}{c}\text { Propellant Utilization } \\
\text { (mass savings) }\end{array}$ & $\begin{array}{c}30 \text { psia left in Tanks at } \\
\text { end-of-life }\end{array}$ & $\begin{array}{c}20 \text { psia left in Tanks at } \\
\text { end-of-life }\end{array}$ \\
\hline Size & $\begin{array}{c}\text { (1) HPA, (3) LPA } \\
520 \mathrm{sq} \text { in }\end{array}$ & $\begin{array}{c}\text { (1) PCM, (3) FCM } \\
40 \mathrm{sq} \text { in }\end{array}$ \\
\hline Mass & $14.5 \mathrm{~kg}$ & $3 \mathrm{~kg}$ \\
\hline
\end{tabular}

These valves along with latch valves and micro pressure and temperature sensors will be integrated into a diffusion-bonded Flow Control Module. Two FCMs are scheduled to be delivered in July 2006 and subsequently tested to TRL 5. During the option phase in 2007, VACCO will focus on development of a XFS controller, fabrication and testing of a Pressure Control Module, and end-to-end testing of these components with an ion thruster.

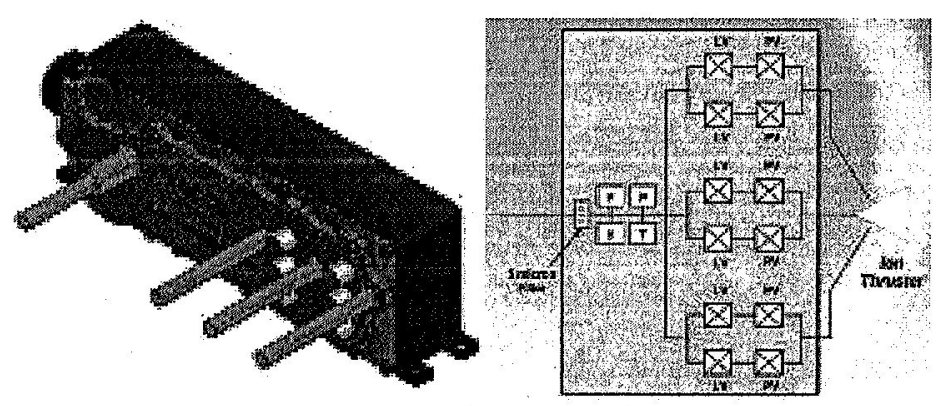

Figure 7: VACCO Flow Control Module and Internal Layout.

\section{Commercial Thruster Systems}

Aerojet has developed and recently completed qualification of the BPT-4000 HET system ${ }^{13}$. There was an opportunity to leverage a significant DOD investment for NASA by extending the life test of the Aerojet thruster. The BPT-4000 life test accumulated more than 5,000 hrs of erosion data that may benefit future Hall erosion models. Because an earth orbiting satellite does not need to operate over large power ranges, the Aerojet qualification test occurred at only four operating conditions. To supplement the erosion modeling data, the life test has been extended to include lower power and lower voltage operation. The magnetic field and performance mapping at $1 \mathrm{~kW}-2 \mathrm{~kW}$ has already been completed, and the life test extension is expected to accumulate an additional $1,000 \mathrm{hrs}$ of data. The erosion data shall be used to further validate HET erosion models that will likely benefit the ongoing HiVHAC development.

\section{Future Planned Activities}

The Solar Electric Propulsion technology area currently has the NEXT and HiVHAC thruster development activities within its portfolio, in addition to potential application of commercially available ion propulsion systems. There is also a possibility for a standard architecture development, discussed below, that could include an integrated PPU and DCIU to reduce the cost of the NSTAR IPST. Because the flight rate of electric propulsion missions is relatively low, a major effort within ISP is to down-select future investments into the systems that yield the most benefit to SMD mission users. 


\section{A. NEXT}

The NEXT program is expected to complete all NRA Phase II aetivities in FY06. These activities include the delivery and environmental testing of the EM PPU, environmental testing of the PM thruster, vibration testing of the integration thruster and gimbal, and integrated IPS testing followed by the final performance evaluation review. The NEXT life test is projected to continue until full demonstration of the qualification level throughput. The life test is expected to continue through 2009.

\section{B. HIVHAC}

The near term plans for the HiVHAC program include the completion of fabrication both the SOA and ASOA thrusters for performance testing. The ASOA thruster is scheduled to begin a long duration wear test starting in October, 2006. Further investment into the HiVHAC program is largely dependent on the outcome of the performance and wear tests.

\section{Advanced Xenon Feed System}

The advanced xenon feed system near term activities include integrated testing of the VACCO flow control module with a thruster. Planned activities include the development of a pressure control module (PCM) for single string PCM-FCM-thruster integrated testing to occur near the end of FY07.

\section{Commercial Thruster Systems}

Commercial ion propulsion systems may have potential application to science missions. ISPT is currently planning to investigate the use the Aerojet BPT-4000 and the Boeing $25 \mathrm{~cm}$ XIPS for SMD applicability. If the commercially available systems can meet science mission objects, there is potential to significantly lower the cost of flight hardware. Topics under consideration include throttleability functionality of the system, spacecraft interfaces and interaction, and necessary testing required to validate and qualify the hardware for science mission requirements.

\section{E. Standard Architecture}

ISP has continued to investigate strategies to help lower the cost of ion propulsion systems for Discovery and New Frontiers class missions. The recent experience with cost growth and complexity of the DAWN IPS has emphasized the critical importance of Standard Architecture to address the needs of SMD cost-capped missions. One SA strategy is to simplify the subsystem architecture into a single string configuration which minimizes crossstrapping within the IPS subsystem. This single-string architecture will likely reduce spacecraft integration costs while hardware and flight software will be developed in a flight like configuration. A key element of this approach is the development of a common power processing unit that is integrated with the Digital Control and Interface Unit. It is likely that the SA PPU/DCIU would be a modular design that is reconfigurable for use with other Ion subsystems.

\section{Acknowledgments}

The work described in this paper was funded in whole or in part by the In-Space Propulsion Technology Program, which is managed by NASA's Science Mission Directorate in Washington, D.C., and implemented by the In-Space Propulsion Technology Project at Marshall Space Flight Center in Huntsville, AL. The program objective is to develop in-space propulsion technologies that can enable or benefit near and mid-term NASA space science missions by significantly reducing cost, mass or travel times.

The authors wish to acknowledge important contributions by the GRC, JPL, Aerojet, and VACCO. 


\section{References}

' Patterson, M. J., et al., “NEXT: NASA's Evolutionary Xenon Thruster Development Status," AIAA 2003-4862, July 2003.

${ }^{2}$ Patterson, M.J., et al., "NEXT Multi-thruster Array Test - Engineering Demonstration," AIAA 2006-5180, July, 2006.

${ }^{3}$ Diaz, E., Foster, J., Patterson, M., "Plume Characterization of a Multi-thruster Array," AIAA 2006-5181, July, 2006.

${ }^{4}$ Pencil, E., et al., "Gridded Faraday Probe Measurements of the NEXT Multi-thruster Array Plume," AIAA 20065182, July, 2006.

${ }^{5}$ McEwen, H., et al., "Characterization of Plasma Flux Incident on a Multi-thruster Array," AIAA 2006-5183, July, 2006.

${ }^{6}$ Foster, J., "Neutralizer Plasma Coupling in a NEXT Multi-thruster Array," AIAA 2006-5184, July, 2006.

${ }^{7}$ Mandell, M., Foster, J., "NEXT Multiple Engine Tests: Modeling and Results," AIAA 2006-5185, July, 2006.

${ }^{8}$ Van Noord, J., "NASA's Evolutionary Xenon Thruster (NEXT) Ion Propulsion System - Technology for NASA Space Science Missions - Service Life Assessment," GRC-NEXT-103, December 21, 2005.

${ }^{10}$ Oh, David, "“"Evaluation of Solar Electric Propulsion Technologies for Discovery Class Missions," AIAA 20054270, $41^{\text {st }}$ Joint Propulsion Conference, Tucson, AZ, July 10-13, 2005.

${ }^{11}$ Manzella, D., Oh, D., Aadland, R., "Hall Thruster Technology for NASA Science Missions," AIAA 2005-3675, $41^{\text {st }}$ Joint Propulsion Conference, Tucson, AZ, July 10-13, 2005.

${ }^{12}$ Yim, J., Keidar,M., and Boyd, I., "An Evaluation of Sources of Erosion in Hall Thrusters," AIAA 2005-3530, 41 Joint Propulsion Conference, Tucson, AZ, July 10-13, 2005.

${ }^{13}$ De Grys, K., "4.5 kW Hall Thruster System Qualification Status," AIAA 2005-3682, $41^{\text {st }}$ Joint Propulsion Conference, Tucson, AZ, July 10-13, 2005. 


\section{In-Space Propulsion Solar Electric Propulsion Program Overview of 2006}

In Space Propulsion Technology Project NASA Marshall Space Flight Center Randy Baggett, Wendy Hulgan, Robert Bechtel \& John Dankanich $42^{\text {nd }}$ AIAA Joint Propulsion Conference July $9-12,2006$ 


\section{FY06 Investments}
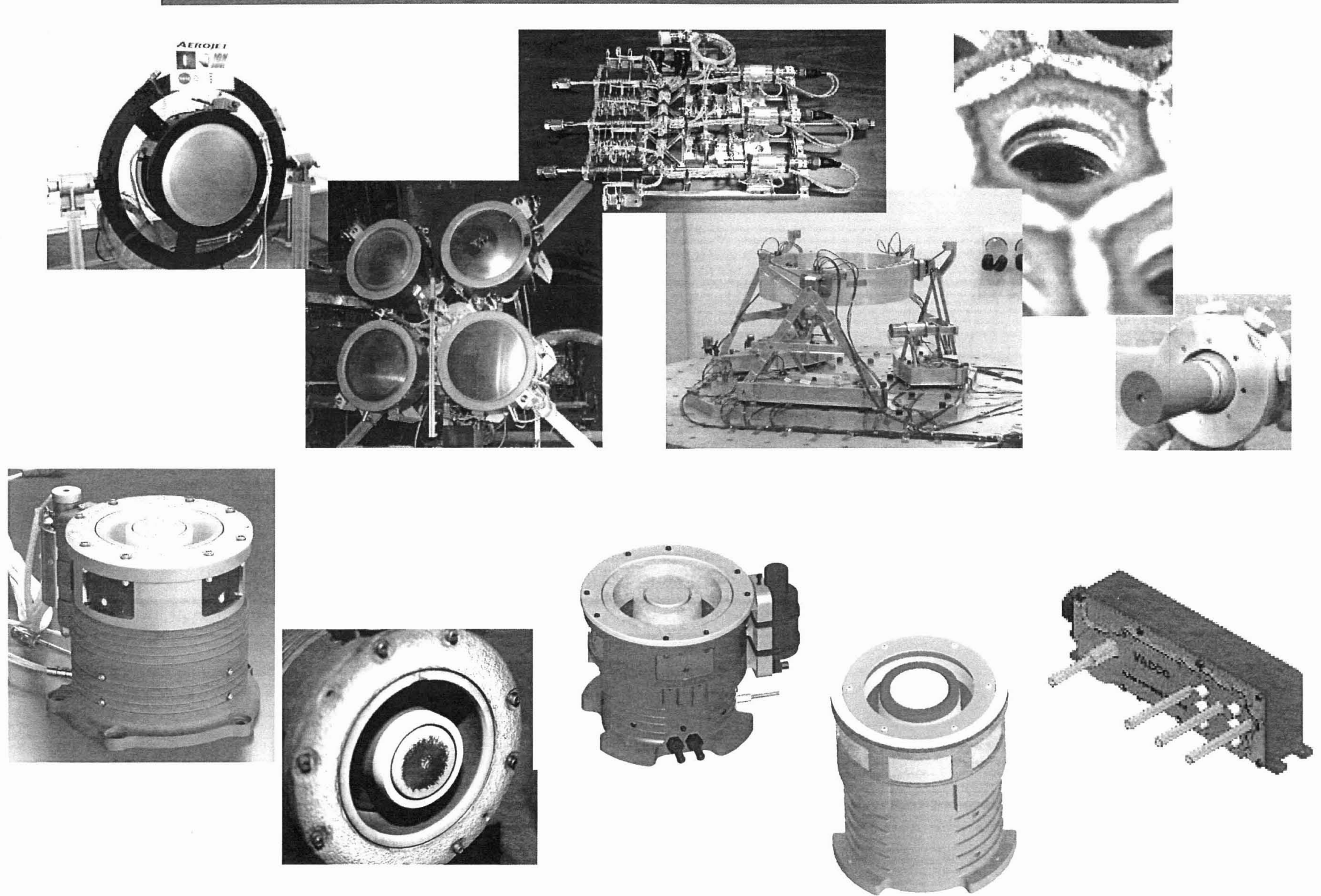


\section{NASA's Evolutionary Xenon Thruster (NEXT)}

- NSTAR 30-cm thruster flew on successful NASA Deep Space 1 mission, will be used on DAWN asteroid rendezvous mission (launch FY07)

- NEXT 40-cm thruster will expand SOA ion thruster capabilities to benefit Discovery/New Frontiers and other NASA science missions

- Reduces number of thrusters required for demanding SMD science missions, reduces total system mass, improves thruster service life

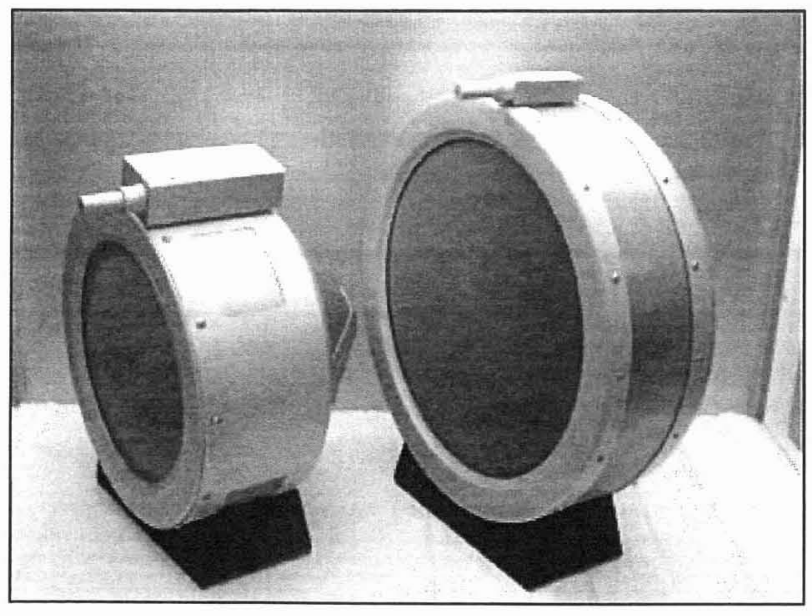

\begin{tabular}{|l|c|c|}
\hline \multicolumn{1}{|c|}{ Thruster Attribute } & NSTAR $^{1}$ & NEXT \\
\hline Max. Input Power, kW & 2.3 & Up to 7 \\
\hline Throttle Range & $4: 1$ & Up to 10:1 \\
\hline Max. Specific Impulse, s & 3,170 & 4,190 \\
\hline Efficiency @ Full Power & $62 \%$ & $71 \%$ \\
\hline Propellant Throughput, kg & 235 & $>300$ (design) \\
\hline Specific Mass, kg/kW & 3.6 & $\sim 2.5$ \\
\hline
\end{tabular}




\section{NEXT Project Background}

- Two-phase project to develop NEXT to TRL-5/-6

- Sponsored by NASA Science Mission Directorate, conducted under MSFC In-Space Propulsion Technology Program

- Implemented through competitive NRA

- Phase 1: one-year base period, completed August 2003

- Phase 2: multi-year (3+) option period, initiated October 2003

- Addresses the entire ion propulsion system:

- Thruster

- Power processing unit (PPU)

- Propellant management system (PMS)

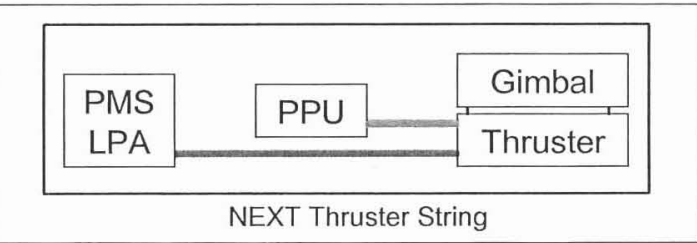

- System integration (including gimbal and control functions)

- NEXT Project Team:

- NASA Glenn Research Center: Technology Project Lead

- NASA Jet Propulsion Laboratory: System Integration Lead

- Aerojet Corp: Thruster, PMS, DCIU simulators

- L3 Comm ETI: Power processing unit

- Participation by Applied Physics Lab, U. Michigan, Colorado State U. 


\section{NEXT Mission Applications}

\begin{tabular}{|c|c|c|c|c|}
\hline Configuration & Typical Mission & $\begin{array}{c}\text { System Input } \\
\text { Power Range }\end{array}$ & Thrust Range & $\begin{array}{c}\text { Total Component Mass } \\
\text { (excl. DClUs) }\end{array}$ \\
\hline \hline $1+1$ & Discovery & $0.6-7.2 \mathrm{~kW}$ & $25-236 \mathrm{mN}$ & $115 \mathrm{~kg}$ \\
\hline $2+1$ & $\begin{array}{c}\text { Discovery. New } \\
\text { Frontiers }\end{array}$ & $0.6-14.4 \mathrm{~kW}$ & $25-472 \mathrm{mN}$ & $172 \mathrm{~kg}$ \\
\hline $3+1$ & Flagship & $0.6-21.6 \mathrm{~kW}$ & $25-708 \mathrm{mN}$ & $229 \mathrm{~kg}$ \\
\hline
\end{tabular}

\section{Discovery Mission Example: Sample Return from Deimos ${ }^{1}$}

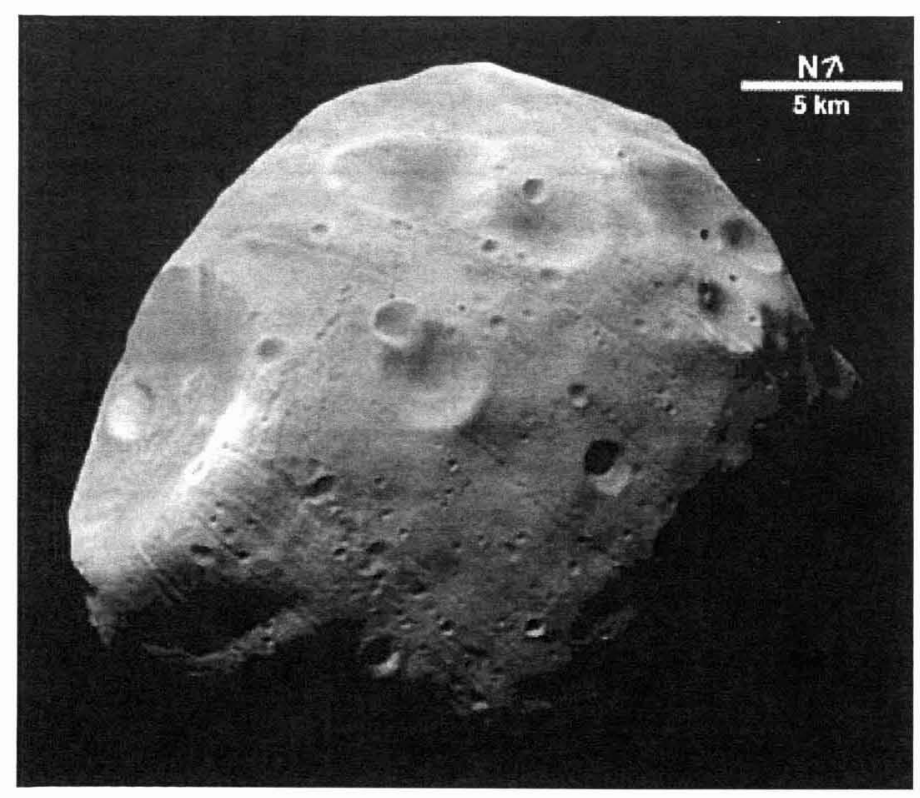

- NEXT SEP system

- 1 operating thruster +1 spare

- Solar array power (1AU, BOL): 10-kW

- Launch Vehicle: Delta II-2925H

- Stay time: 90 days

- Total roundtrip transfer time: 2.91 years

- EP $\Delta \mathrm{V}: 10.04 \mathrm{~km} / \mathrm{s}$

- Mass breakdown:

- Launch mass: 1,065 kg (C3 =13.9 km2/s2)

- Xenon propellant mass: $230 \mathrm{~kg}$

- Final mass: $835 \mathrm{~kg}$ 


\section{NEXT Thruster Manufacturing}

- Aerojet delivered first PM thruster to GRC in January 2006.

- Final Mass $=12.7 \mathrm{~kg}$

- Optics Assembly = $3.26 \mathrm{~kg}$

Optics alignment within $11 \mu \mathrm{m}$ and $7.3 \mu \mathrm{m}$ in the radial and axial directions

- Optics can be assembled and measured in less than seven hours

- Repeatable assembly within $1.3 \mu \mathrm{m}$ !

Cathode assemblies passed $10^{-8}$ sccs He leak test

- DCA Mass $=550 \mathrm{~g}$

- $\mathrm{NCA}$ Mass $=470 \mathrm{~g}$

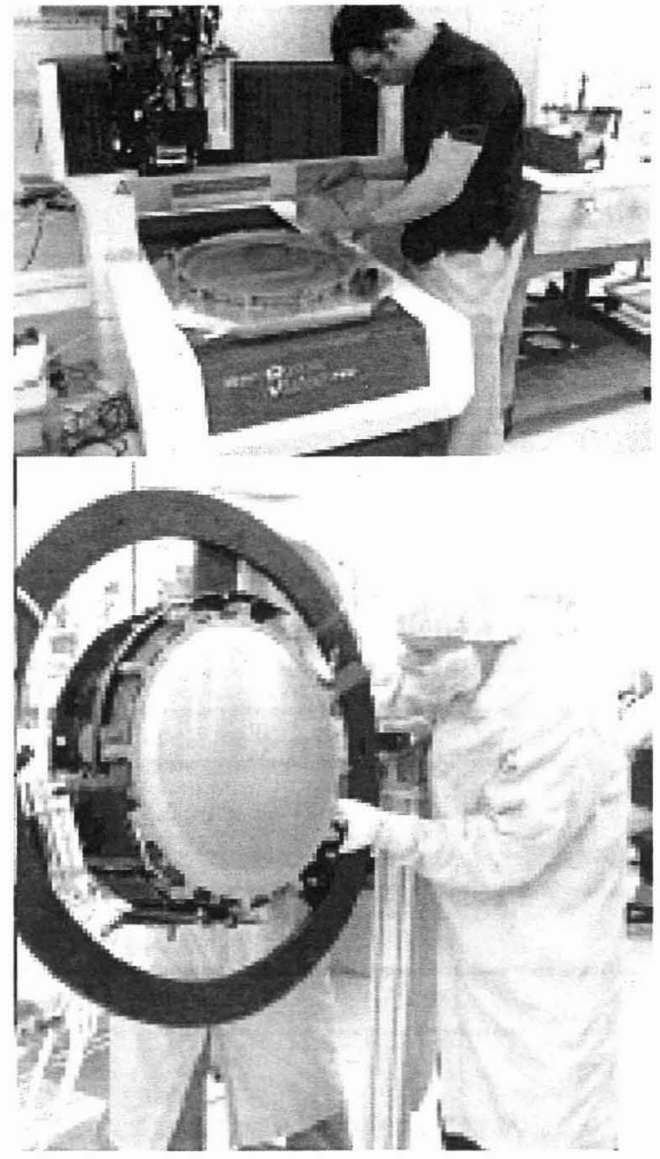




\section{NEXT Thruster Performance}

- PM1 Thruster Performance Acceptance Test (PAT) completed in February 2006.

- Required to operate $>67 \%$ efficiency and $>4,050 \mathrm{~s} \mathrm{I}_{\mathrm{sp}}$ at full power

- Thruster operated from $0.551 \mathrm{~kW}-6.859 \mathrm{~kW}$

\begin{tabular}{c|c|c||c|c|c|c|c|c|} 
Vb, $\mathbf{V}$ & Jb, A & Pin, kW & $\begin{array}{c}\text { TRV Eff. } \\
\text { Req. }\end{array}$ & $\begin{array}{c}\text { Thrust } \\
\text { Eff. }\end{array}$ & $\begin{array}{c}\text { TRV Thrust } \\
\text { Req., } \mathrm{mN}\end{array}$ & $\begin{array}{c}\text { Thrust. } \\
\mathrm{mN}\end{array}$ & $\begin{array}{c}\text { TRV Isp } \\
\text { Req., sec }\end{array}$ & Isp, sec \\
\hline \hline 1800 & 3.524 & 6.860 & 0.708 & 0.710 & 236 & 237 & 4188 & 4190 \\
\hline 1180 & 3.525 & 4.700 & 0.677 & 0.680 & 192 & 192 & 3393 & 3395 \\
\hline 1800 & 2.003 & 3.990 & & 0.711 & & 134 & & 4315 \\
\hline 1179 & 2.002 & 2.750 & & 0.676 & & 108 & & 3495 \\
\hline 1800 & 1.202 & 2.435 & 0.645 & 0.647 & 80 & 80 & 3999 & 4000 \\
\hline 1179 & 1.203 & 1.715 & 0.606 & 0.606 & 65 & 65 & 3240 & 3245 \\
\hline 679 & 1.202 & 1.135 & & 0.524 & & 49 & & 2455 \\
\hline
\end{tabular}

NEXT PM thruster met or exceeded all TRV requirements

- PAT exposed one rework item:

- Delayed ignition due to DCA excessive heat conduction

- Issue has been resolved and will be further validated with PM2 build 


\section{NEXT Multi-thruster Array Testing}

Objective: Determine the effect of multi-thruster operation on grid life, plasma particles and field distribution, performance parameters and dormant thrusters.

- Completed NEXT multi-thruster array tests in December 2005

- Demonstrated 1+1, 2+1, and 3+1 thruster configurations

- Testing two operating thrusters with $0.64 \mathrm{~m}$ and $0.91 \mathrm{~m}$ separation distances

- EM1 mounted on a gimbal with $12^{\circ}$ rotation

- Thrusters operated with various cathode configurations

- Various separation distances

- Single cathode, multi-thruster operation
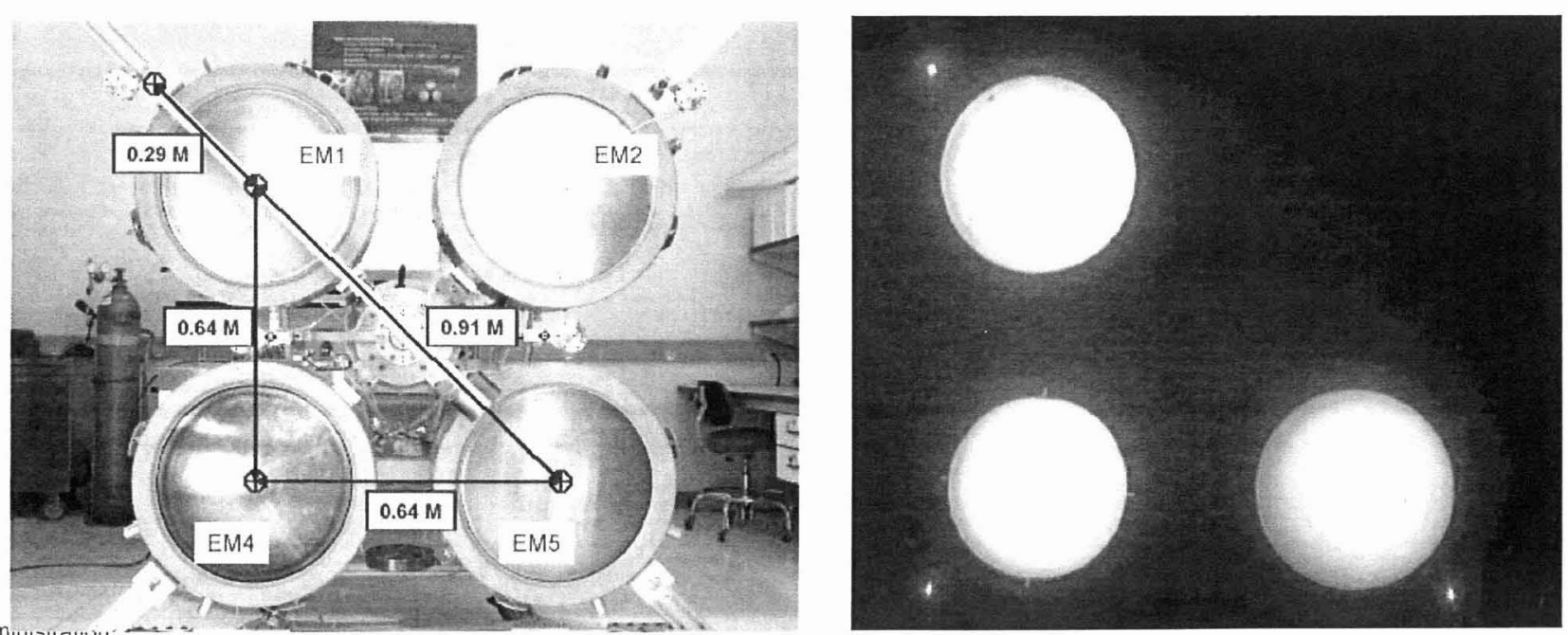


\section{Multi-thruster Array Testing Cont.}

\section{Summary:}

- The performance observed for a thruster appears to be consistent with single thruster operation.

- No indication thruster parameters that effect life are altered during multi-thruster operation.

- Thruster gimbaling does not alter the functionality of the gimbaled or adjacent thrusters.

- A single neutralizer for multiple thrusters may be a viable fault recovery mode

- No plume-to-plume interactions observed

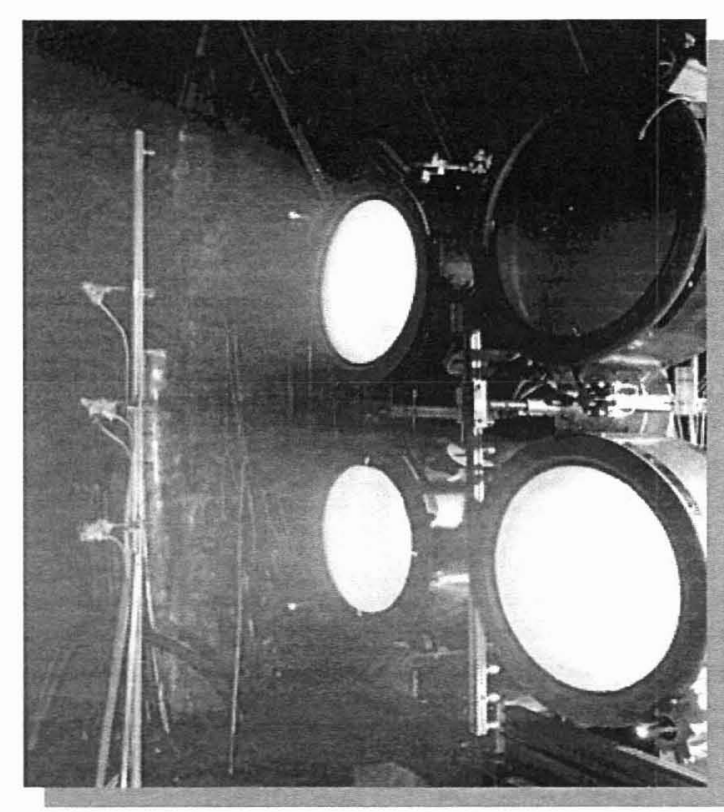

NEXT Multi-thruster Testing Session: Wednesday at 2:00 PM, Session 131-EP31 


\section{NEXT EM3 Wear Testing}

- NEXT EM3 wear testing began June 5, 2005.

- EM3 is a GRC built thruster with Aerojet built PM optics.

- Predicted life assessment $>730 \mathrm{~kg}$.

- Baseline plan is to demonstrate $450 \mathrm{~kg}$ of throughput.

- As of July 1st: $>5,300$ hours of operation and $>120 \mathrm{~kg}$ of Xenon

\begin{tabular}{|c|c|c|c|c|c|}
\hline \multirow[b]{2}{*}{ Component } & \multirow[b]{2}{*}{ Failure Mechanism } & \multicolumn{4}{|c|}{ Xenon Throughput, kg } \\
\hline & & $\begin{array}{l}3.52 \mathrm{~A} I_{b} \\
1800 \mathrm{~V} V_{b}\end{array}$ & $\begin{array}{l}1.20 \mathrm{~A} I_{b} \\
1800 \mathrm{~V} V_{b}\end{array}$ & $\begin{array}{l}1.20 \mathrm{~A} I_{b} \\
1179 \mathrm{~V} V_{b}\end{array}$ & $\begin{array}{l}1.20 \mathrm{~A} I_{b} \\
679 \mathrm{~V} V_{b}\end{array}$ \\
\hline \multirow{3}{*}{ DCA } & Insert Barium Depletion & 1450 & 5200 & 4100 & 3700 \\
\hline & Excessive Wear of Orifice Plate & \multicolumn{4}{|c|}{ No excessive wear prior to excessive keeper wear } \\
\hline & Excessive Wear of Keeper & 1800 & TBD & TBD & TBD \\
\hline \multirow{4}{*}{ NCA } & Insert Barium Depletion & 1600 & 2400 & 2400 & 2400 \\
\hline & Excessive Wear of Orifice Plate & \multicolumn{4}{|c|}{ No excessive wear } \\
\hline & Excessive Wear of Keeper & $>800$ & TBD & TBD & TBD \\
\hline & Neutralizer orifice clogging & \multicolumn{4}{|c|}{ Controlled through requirements } \\
\hline \multirow{2}{*}{$\begin{array}{l}\text { Accelerator } \\
\text { Electrode }\end{array}$} & $\begin{array}{l}\text { Pit and Groove Wear / } \\
\text { Structural Failure }\end{array}$ & $>730$ & $>800$ & TBD & TBD \\
\hline & $\begin{array}{l}\text { Aperture Enlargement / } \\
\text { Electron Backstreaming }\end{array}$ & $>730$ & $>800$ & TBD & TBD \\
\hline $\begin{array}{l}\text { Screen } \\
\text { Electrode }\end{array}$ & Excessive Wear & \multicolumn{4}{|c|}{ No excessive wear anticipated } \\
\hline $\begin{array}{l}\text { Optics } \\
\text { Assembly }\end{array}$ & An Unclear able Short & \multicolumn{4}{|c|}{ Controlled through requirements } \\
\hline \multirow{2}{*}{$\begin{array}{l}\text { Discharge } \\
\text { Chamber }\end{array}$} & $\begin{array}{l}\text { Flake Retention of Sputtered } \\
\text { Material }\end{array}$ & 1850 & TBD & TBD & TBD \\
\hline & $\begin{array}{l}\text { Magnet Temperatures } \\
\text { Excessive }\end{array}$ & \multicolumn{4}{|c|}{$100^{\circ} \mathrm{C}$ margin (dependent on mission) } \\
\hline $\begin{array}{l}\text { High Voltage } \\
\text { Propellant } \\
\text { Isolators }\end{array}$ & $\begin{array}{l}\text { Deposition of Sputter Material } \\
\text { Degrading Voltage Standoff }\end{array}$ & \multicolumn{4}{|c|}{$\begin{array}{c}\text { Monitoring of manufacturing process, Design } \\
\text { verification test ongoing }\end{array}$} \\
\hline
\end{tabular}




\section{NEXT EM3 Wear Testing Cont.}

- No change in thruster performance to date
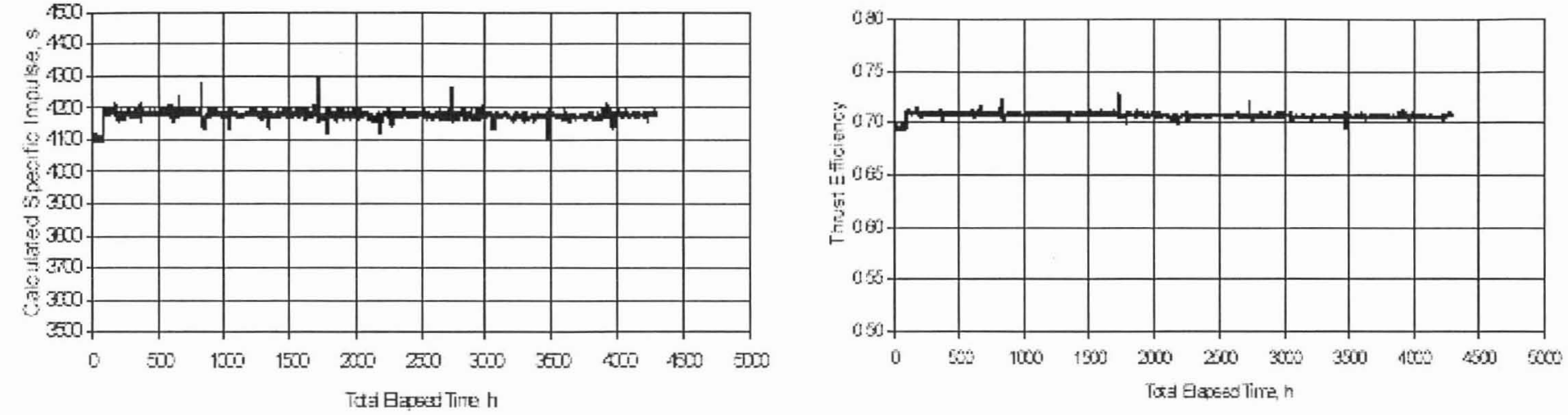

- No change in grid gap observed

- Frocinnconsisi
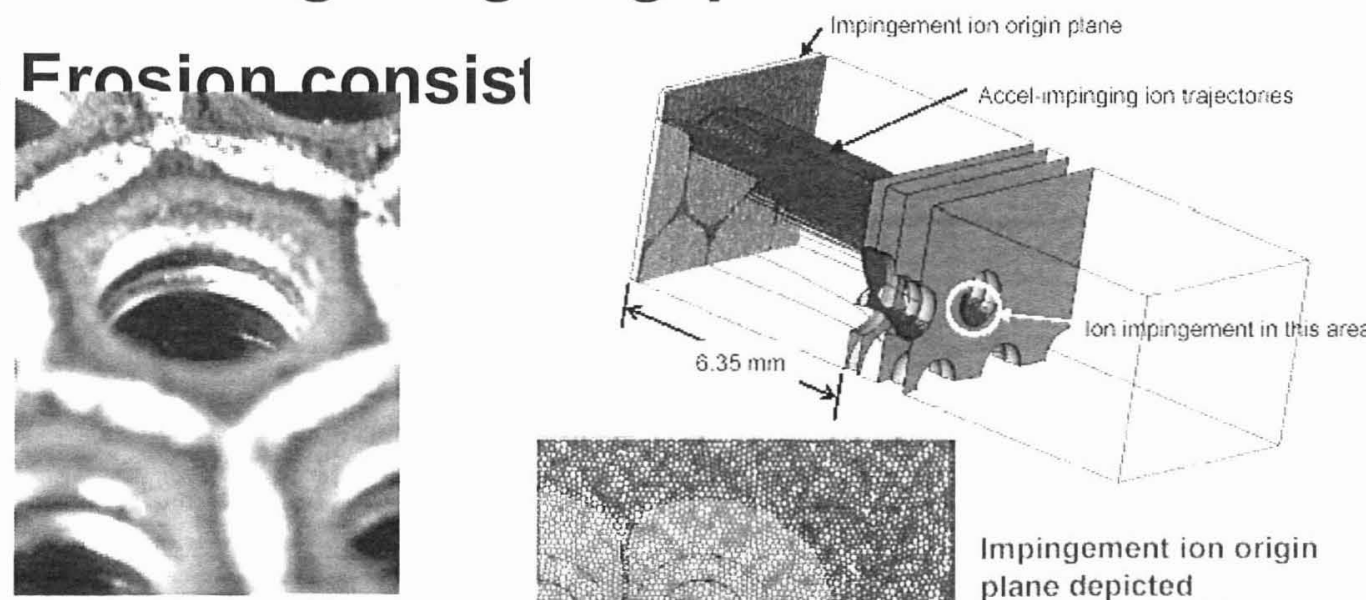

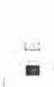
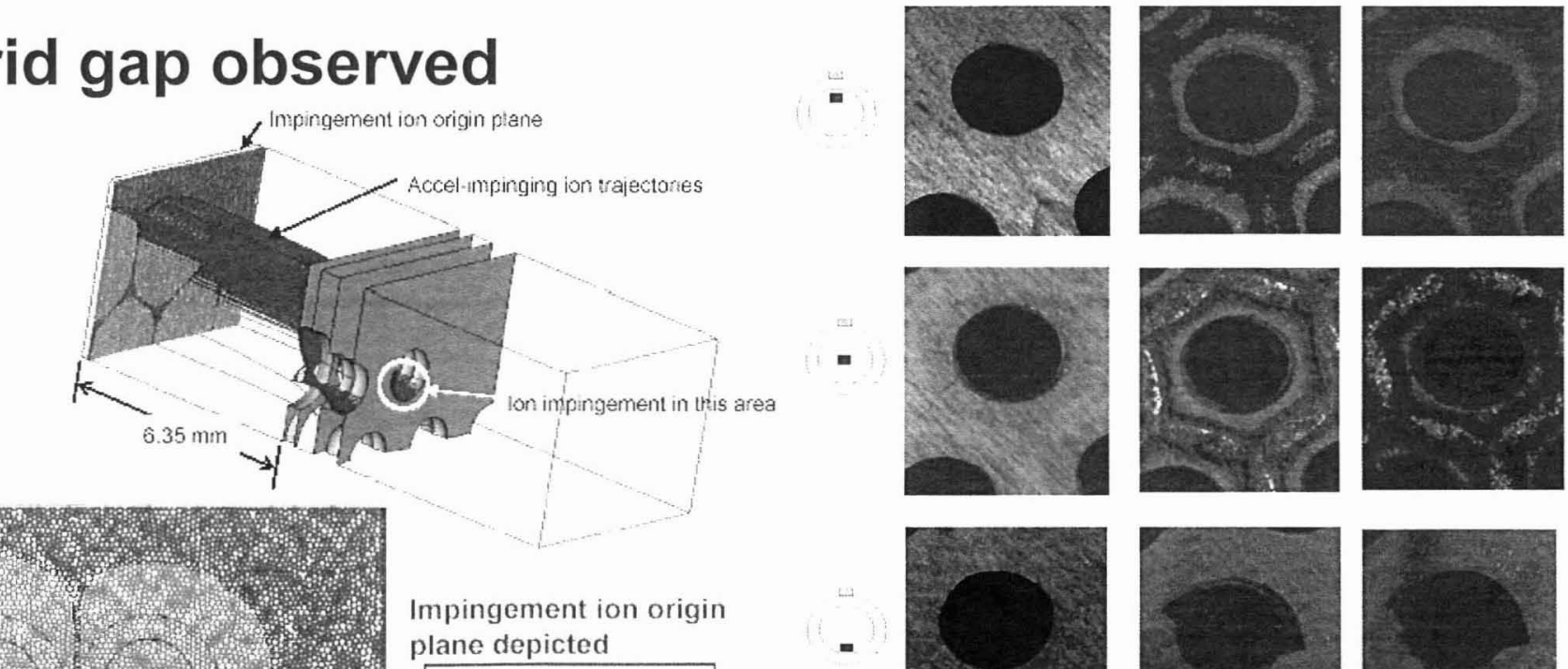

mpingement ion origin plane depicted

\begin{tabular}{l} 
- Passes through aperture \\
- Strikes screen gnd \\
- Strikes accelerator grid \\
\hline
\end{tabular}
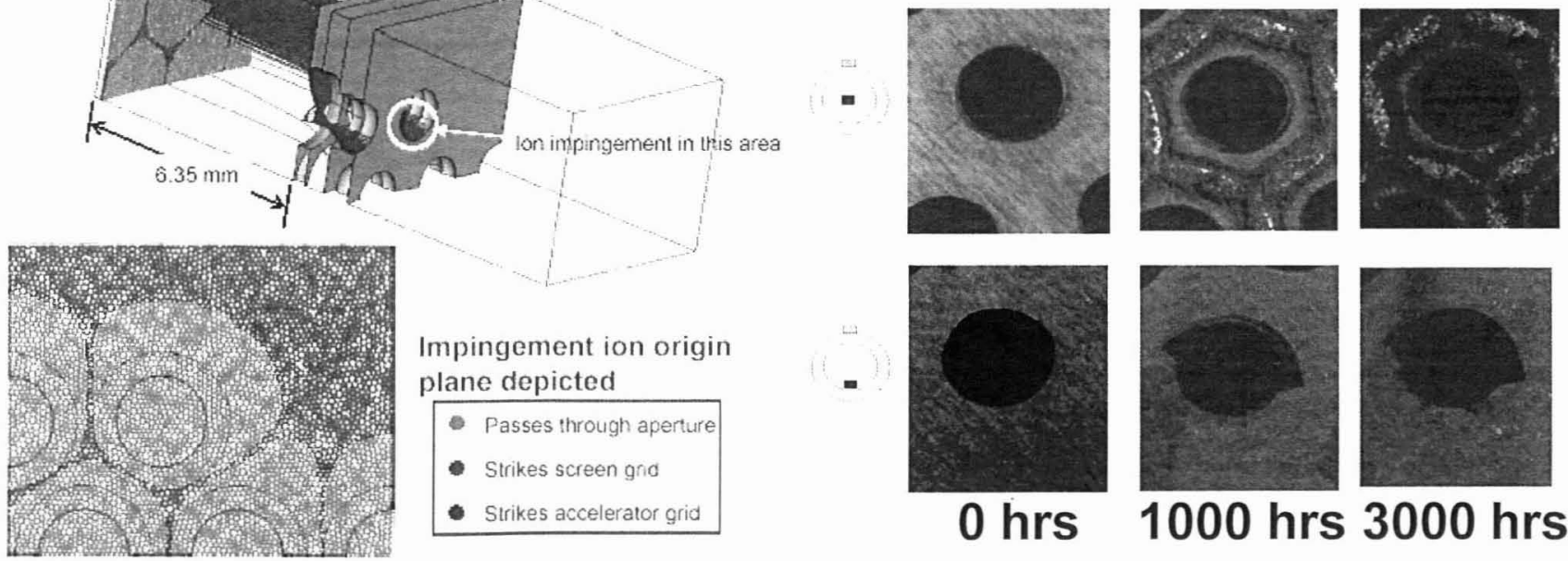


\section{NEXT PPU, PMS and Gimbal}

- The EM PPU is being developed by L-3.

- Modular design for increased manufacturability and decreased cost.

- PPU efficiency ranges from approximately 90\% - 95\% from minimum to maximum power.

- PPU is completing final assembly with delivery expected late summer.

- Estimated mass is $34.6 \mathrm{~kg}$.

- The EM PMS is being developed by Aerojet.

- Independent control of main, DCA and NCA flow rates.

- HPA and LPA complete included vibration testing

- Final single string mass is $9.2 \mathrm{~kg}$.

- The BB gimbal is developed by JPL and Swales.

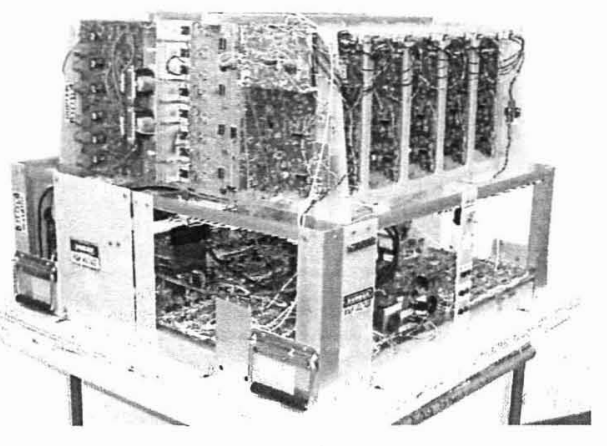

- Gimbal thruster integrated environmental testing to occur end of July.

- Gimbal rotation > $15^{\circ}$

- Final mass is $5.98 \mathrm{~kg}$.
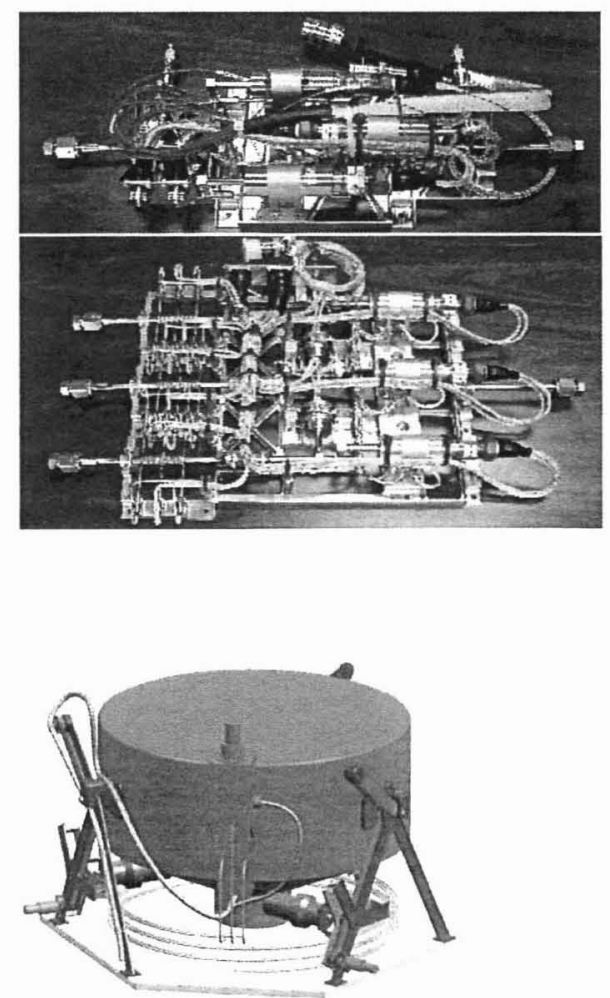


\section{NEXT Environmental Testing}

- NEXT Thruster thermal vacuum and vibration testing at JPL planned for July and September respectively.

- Gimbal shock and vibration test completed in March 2006 with a mass simulator.

- NEXT PPU environmental testing planned for fall 2006.

- NEXT PMS vibration testing completed in FY05 with thermal vacuum testing scheduled for FY07.
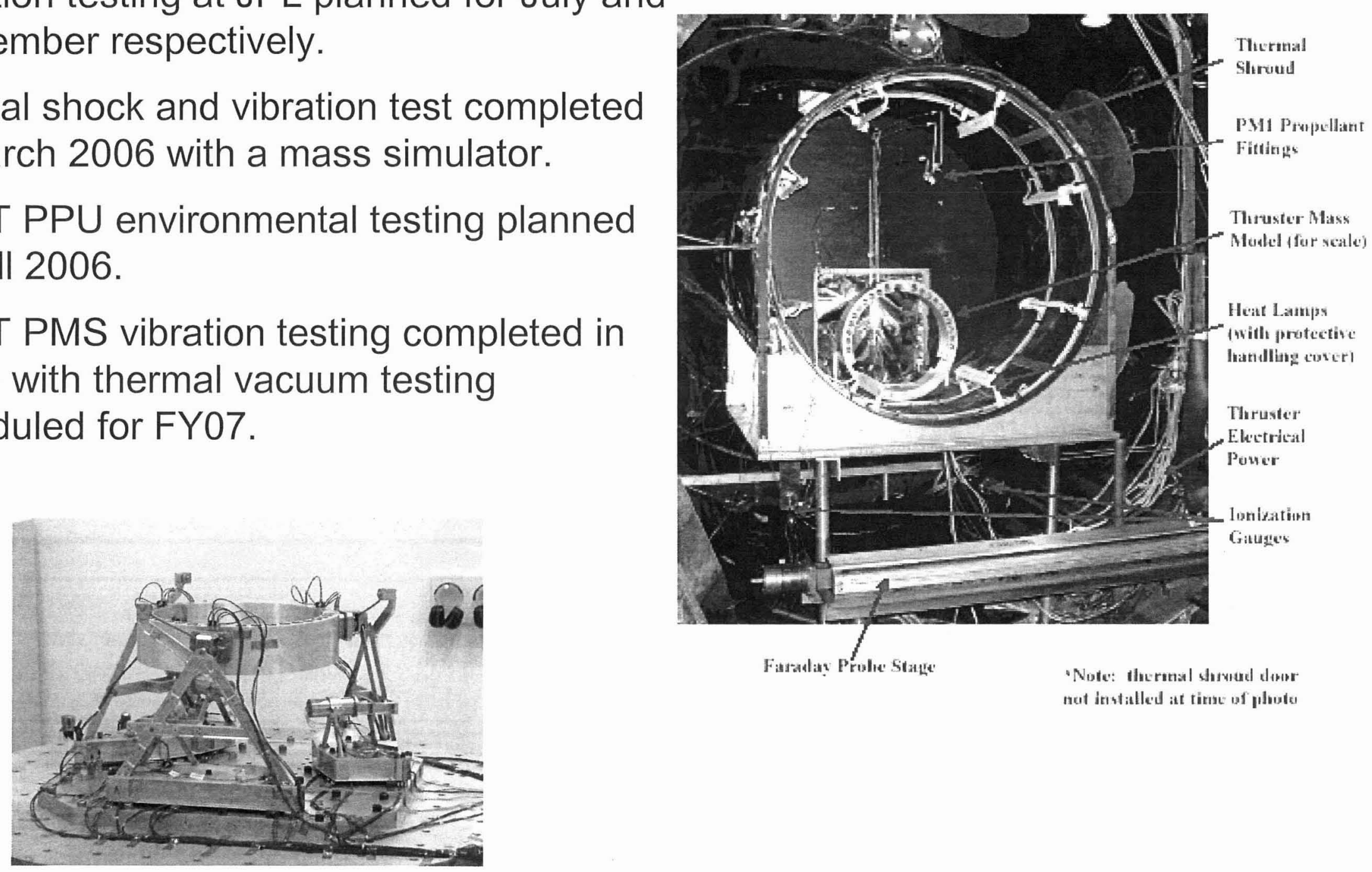


\section{NEXT Future Work}

- The NEXT PM1 thruster, gimbal, and PPU will complete environmental testing later this summer and fall.

- Integrated system testing to begin October 2006.

- The NEXT PM2 delivery will further demonstrate thruster manufacturability and technology transfer.

- PER to be help end of FY07

NEXT available with full life qualification by 2009! 


\section{High Voltage Hall Accelerator (HiVHAC)}

- Optimize Hall thrusters for NASA SMD missions

- Operate at high voltage $(\sim 1000-V)$ to increase specific impulse

- Operate at higher power density to increase thruster efficiency

- Mitigate channel erosion to increase throughput and total impulse

- Primary HiVHAC Products:

- SOA Design: NASA-94-M thruster with discharge channel walls thick enough to enable $150 \mathrm{~kg}$ of propellant throughput (Aerojet led design)

- Advanced SOA Design: NASA-103M thruster with in-situ replacement of eroded channel walls to enable $300 \mathrm{~kg}$ of propellant throughput (GRC led design)

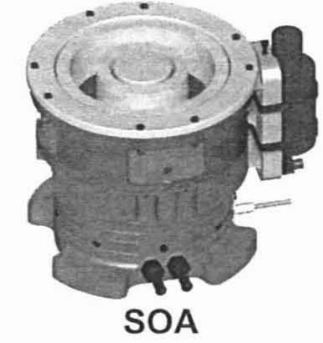

- Numerical simulations of discharge channel erosion, validated with detailed experimental diagnostics using NASA-77M thruster (GRC, U. Michigan)

- An EM SOA and LM ASOA thruster undergoing final assembly

- Fabrication to be complete July 2006

- Performance testing to begin August 2006

- Long duration wear testing of ASOA thruster to begin October 2006 


\section{High Voltage Hall Accelerator (HiVHAC)}

- Design Objectives:

\begin{tabular}{|c|c|}
\hline Input Power & $0.3-3.6 \mathrm{~kW}$ \\
\hline Specific Impulse & $1600-2700 \mathrm{~s}$ \\
\hline Efficiency & $>60 \%$ \\
\hline Thrust & $20-150 \mathrm{mN}$ \\
\hline Propellant Throughput & $>150 \mathrm{~kg}(\mathrm{SOA})$ \\
& $300 \mathrm{~kg}(\mathrm{ASOA})$ \\
\hline Specilic Mass & $1.3 \mathrm{~kg} / \mathrm{kW}$ \\
\hline Operational Life & $10.000 \mathrm{hrs}$ \\
\hline
\end{tabular}

Combined with lower system complexity, low power HiVHAC thrusters offer significant benefits for NASA Discovery missions

- Mission Example: DAWN cost and performance comparison

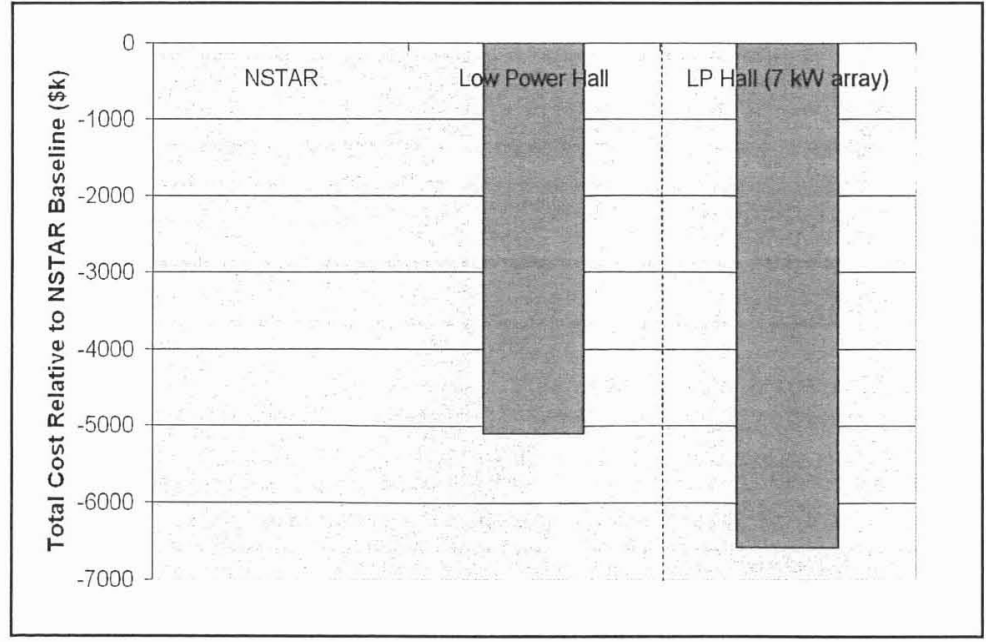

Reduced cost relative to NSTAR baseline

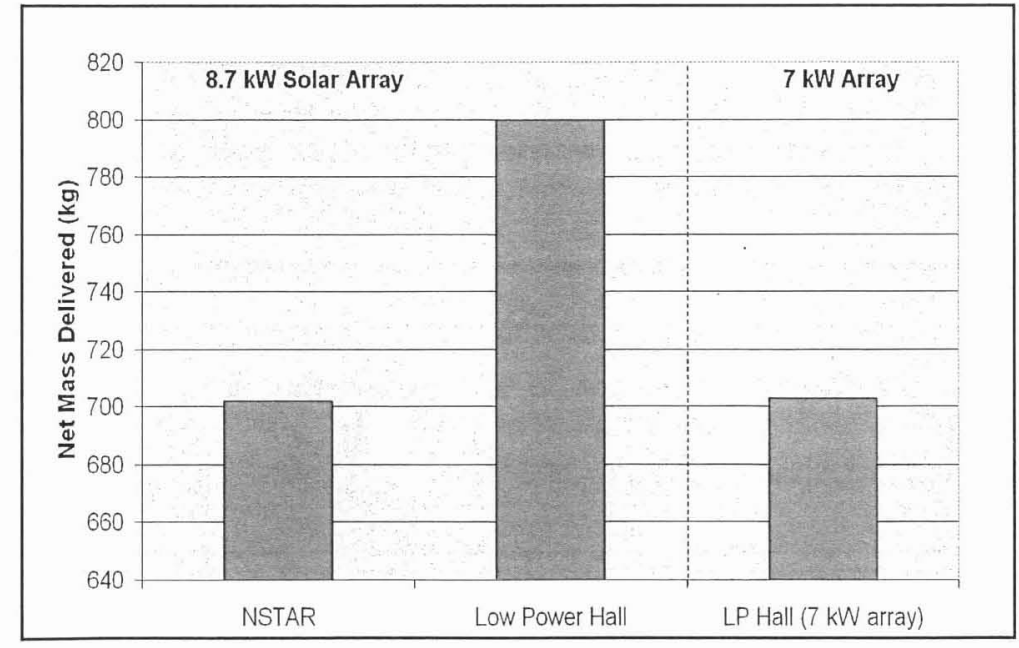

Increased payload relative to NSTAR baseline 


\section{BPT-4000 Life Extension}

- ISP has funded a life test extension on the Aerojet BPT-4000 Hall Thruster

- Thruster erosion data to support Hall modeling

- Initial 5,000 hrs of testing

- Additional low power erosion data

- Demonstrate low power operation for SMD applicability

- Increased demonstrated capability to reduce risk

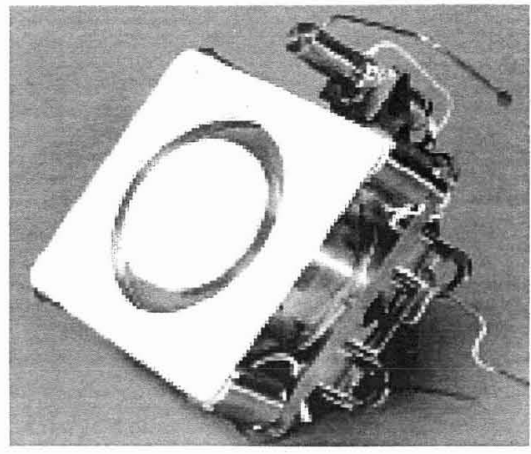

\begin{tabular}{|l|c|c|c|c|l|}
\hline & \multicolumn{2}{|c|}{ Life Test Results } & \multicolumn{2}{|c|}{$\begin{array}{c}\text { Usable Flight Limits } \\
\text { (50\% Margins) }\end{array}$} & \\
\hline Test Description & $\begin{array}{c}\text { Throughput } \\
(\mathbf{k g})\end{array}$ & $\begin{array}{c}\text { Total } \\
\text { Impulse } \\
(\mathrm{MN}-\mathbf{s})\end{array}$ & $\begin{array}{c}\text { Throughput } \\
\text { (kg) }\end{array}$ & $\begin{array}{c}\text { Total } \\
\text { Impulse } \\
\text { (MN-s) }\end{array}$ & Notes \\
\hline NSTAR & 235 & 7.2 & 157 & 4.8 & Completed \\
\hline BPT-4000-5.600 h Life Test & 258 & 4.8 & 172 & 3.2 & Completed FY2005 \\
\hline BiP -4000 - Phase One Extension & 292 & 5.3 & 195 & 3.5 & FY2006 \\
\hline BPT-4000 - Phase Two Extension & 427 & 7.3 & 285 & 4.9 & Funding TOD for FY2007 \\
\hline
\end{tabular}

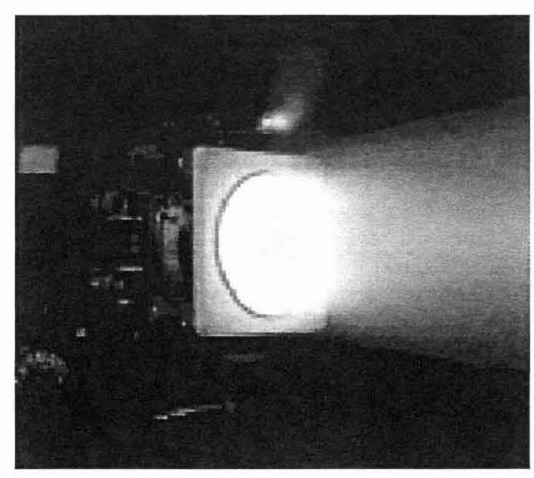

- BPT-4000 has potential for Discovery missions due to reduced cost of IPS 


\section{Hall Wear Characterization and Modeling}

- University of Michigan developing Hall erosion models for HiVHAC program

- Comparison to SPT-100 and HiVHAC wear data

- NASA-77M HiVHAC data obtained at multiple voltages

- BPT-4000 data to be incorporated when available

- JPL developing cathode life models

- Future plans include life modeling with realistic mission throttle profile analysis
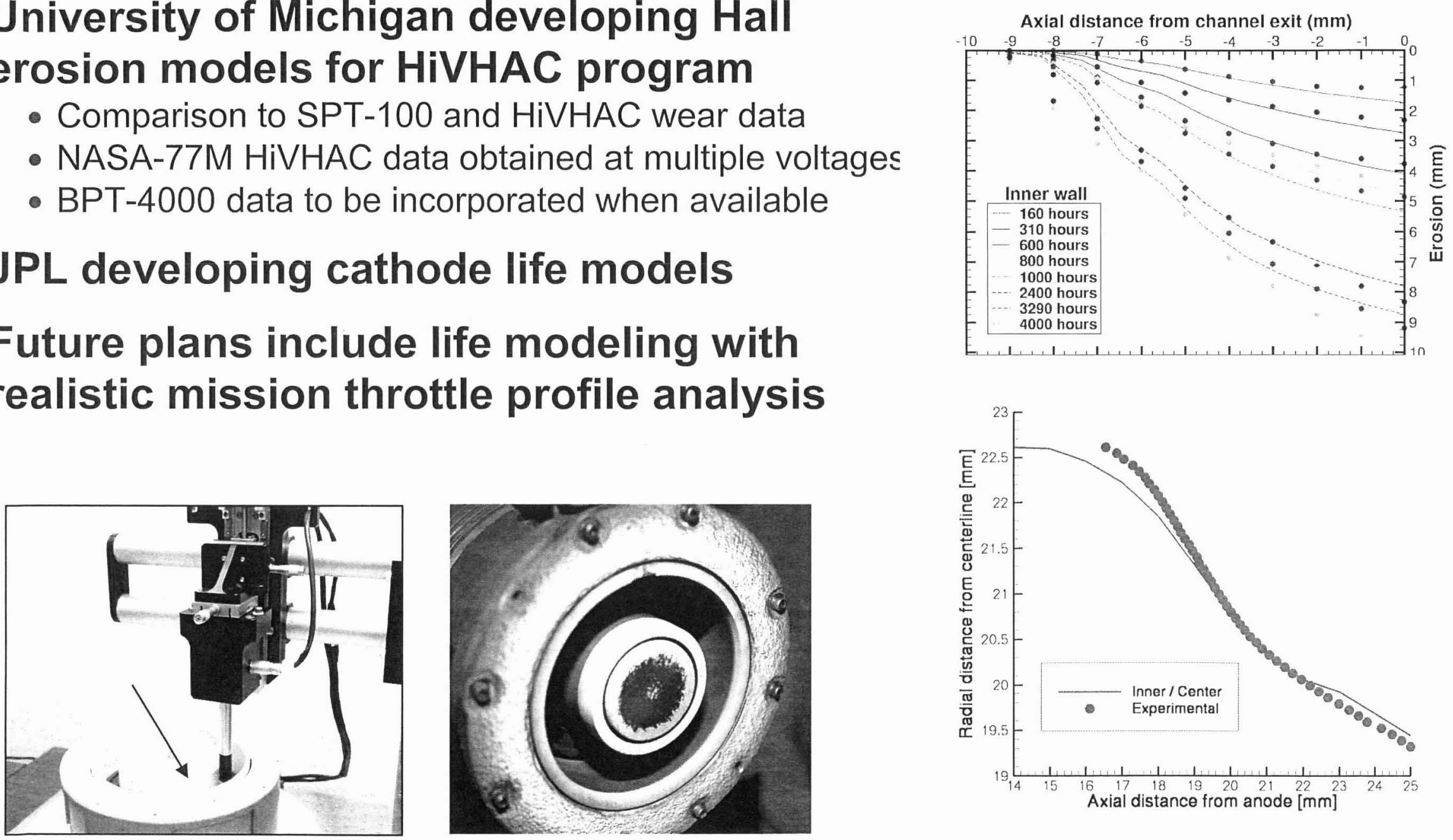

Comparison of SPT (Top) and HiVHAC (Bottom) experimental vs. predicted erosion. 


\section{Advanced Feed Systems}

- VACCO's lightweight reliable xenon feed system was awarded in 2004 to develop a feed system with increased reliability while decreasing the system mass and volume.

- Current development activities include:

- Diffusion bonded Flow Control Module (FCM)

- Two FCM's expected in July 2006

\begin{tabular}{c|c|c|} 
& NEXT & VACCO \\
\hline Footprint & $0.34 \mathrm{~m}^{2}$ & $0.03 \mathrm{~m}^{2}$ \\
\hline Mass & $14.5 \mathrm{~kg}$ & $3 \mathrm{~kg}$ \\
\hline
\end{tabular}

- Tested to TRL 5

- Design of Pressure Control Module (PCM)

- Future plans include development of an XFS controller, build and test of a PCM, and end-to-end testing with an ion thruster.
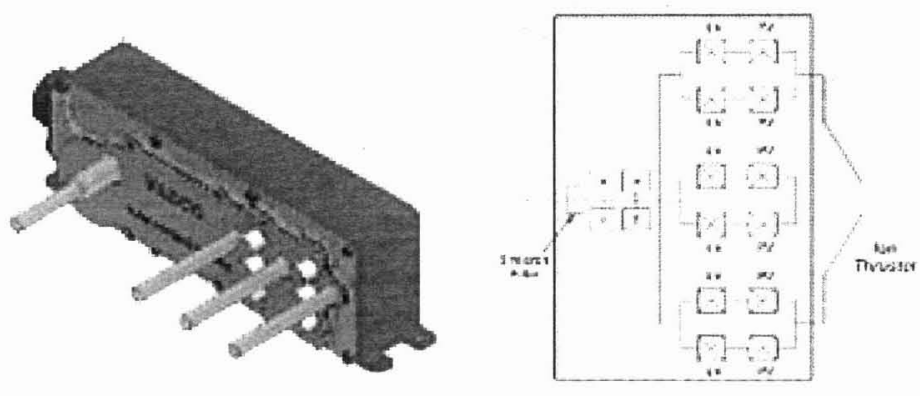


\section{Future Plans}

\section{Standard Architecture}

Objective: reduce electric propulsion system NRE costs by standardizing components and increasing manufacturability of sub-systems

- Single-string architecture to reduce system costs

- Operate various thrusters to match mission needs

- NEXT, NSTAR, possibly commercial thrusters (XIPS)

- Standardize power supply topologies

- Embed DCIU to reduce production costs

- Standardize propellant management systems (LPA, HPA, VACCO, etc)

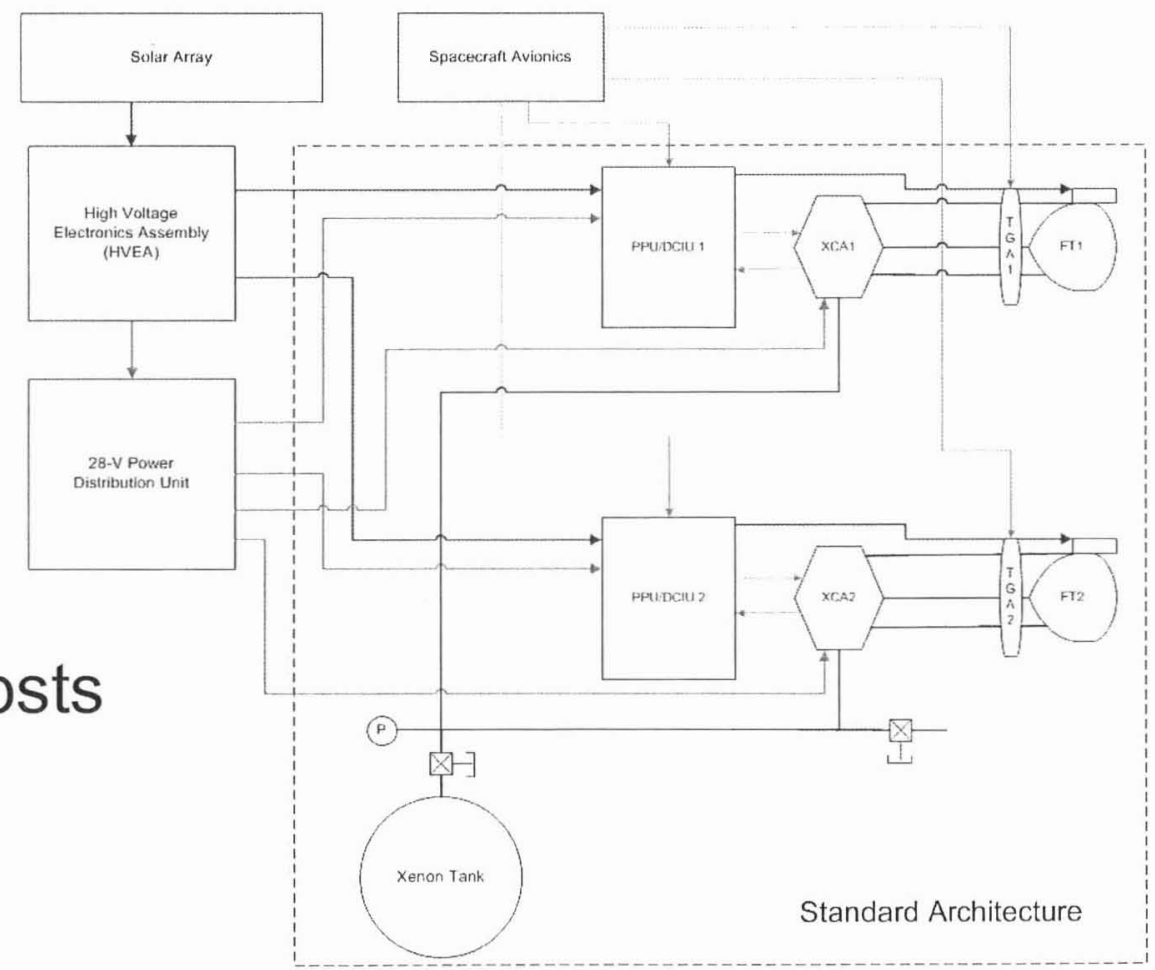

\section{Status:}

- PPU/DCIU design selection in FY06, initiate procurement in FY07 


\section{Future Plans}

\section{Develop Life Qualification Standards}

\section{Objective: improve method for thruster life qualification}

- Thruster life qualification for SMD missions currently require several thousand to tens of thousands of hours of vacuum ground tests

- Expensive and time consuming; roadblock to user acceptance

- Ongoing activities at NASA centers, industry, and universities to model ion and hall thruster erosion characteristics, predict thruster lifetimes

- Ion grid erosion

- Discharge cathode erosion

- Hall thruster chamber erosion

- Need to establish a set of standards for electric propulsion thruster life qualification using combination of numerical models and limited ground test validation

- Establish expert working group to develop standards, with SMD and TMCO participation (represent user community)

- Identify, develop and validate remaining ion and hall thruster life models

- Publish standards documents for community acceptance and use 


\section{Related JPC Presentation and Papers}

- NEXT Multi-thruster Array Test - Engineering Demonstration

- Plume Characterization of a Multi-thruster Array

- Gridded Faraday Probe Measurements of the NEXT Multi-thruster Array Plume

- Characterization of Plasma Flux Incident on a Multi-thruster Array

- Neutralizer Plasma Coupling in a NEXT Multi-thruster Array

- NEXT Multiple Engine Tests: Modeling and Results 


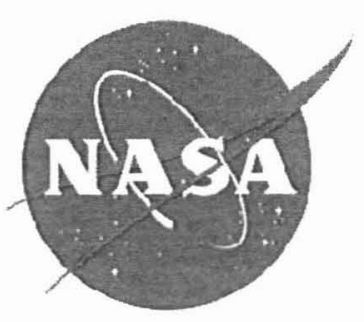

www.nasa.gov 


\section{Backup Slides If applicable}


For additional information on the Solar Electric Propulsion task areas within the In-Space Propulsion Program, please contact:
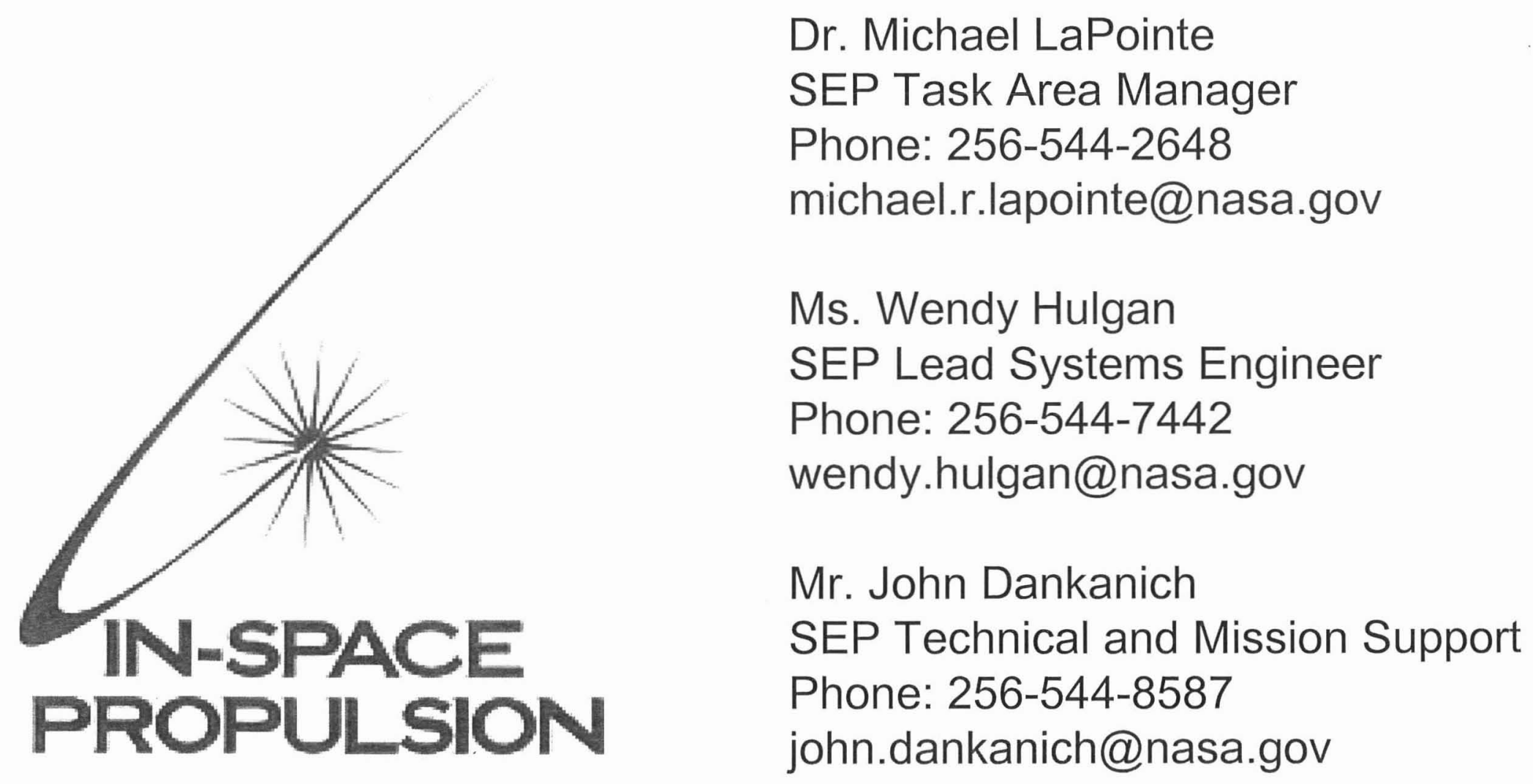